\title{
Combination of HVSR and MASW Methods to Obtain Shear Wave Velocity Model of Subsurface in Israel
}

\author{
Marina Gorstein and Michael Ezersky* \\ Geophysical Institute of Israel
}

\begin{abstract}
Estimating possible site effect is an integral part of evaluation of the seismic hazard and reduction of earthquake damages. In regions with low or moderate seismicity as in Israel, the site response should be determined by analytical tools. These computations require knowledge of the subsurface geological structure in terms of shear-wave velocity (Vs) profile down to seismic bedrock. Conventionally, this problem is resolved by joint implementation of Horizontal-to-Vertical Spectral Ratios (HVSR or Nakamura's) technique, which is based on ambient noise measurements and seismic methods such as S-wave refraction or Multichannel Analysis of Surface Waves (MASW) method. The first one does not allow deep penetration of seismic waves because of its weak source. The MASW method using $4.5 \mathrm{~Hz}$ geophones is restricted in penetration depth of surface waves because of frequency (wavelength) limitations. In this study, we have applied $2.5 \mathrm{~Hz}$ geophones and special data processing to provide constructing Vs section to a depth of $100 \mathrm{~m}$ and deeper. In combination with HVSR measurements, MASW enables constructing reliable subsurface model, which could be integrated into the seismic hazard assessment. Testing of this combined methodology was carried out at a number of sites with differing geological structures in Israel.
\end{abstract}

Keywords: ambient noise, HVSR method, shear wave velocity subsurface structure, surface waves

\section{Introduction}

Subsurface ground conditions, which might cause significant amplifications due to high impedance contrast between soft soils and a firm basement, requires the need to estimate the expected ground motions and determine the main characteristics of the seismic response of the underground (i.e. resonance frequencies and amplifications) for the seismic hazard assessment and risk mitigation.

Techniques developed to identify the main characteristics of site responses for soft deposits (i.e. resonance frequencies and amplification factor) may be grouped into three main categories (Bonnefoy-Claudet et al 2006):

1) A numerical simulation approach coupled with classical geophysical and geotechnical tools (such as seismic refraction, seismic reflection, boreholes, penetrometers, etc.) in order to provide reliable estimates of the required input parameters including thickness, density, damping and S-wave velocity of different soil and rock layers at a site.

2) Direct measuring of the site response on the basis of earthquake recordings on specific stations located at carefully chosen sites.

3) Methods based on ambient noise recordings.

The first group of methods based on utilization of seismic exploration to determine subsurface structural models may be very expensive. Moreover, predicting site effect parameters based on models inferred from geological and geophysical information only, may differ significantly from experimental estimation (Zaslavsky et al 2005, 2008, and 2009).

The second technique (Jarpe et al 1988, Satoh et al 1995) provides an unbiased experimental

* Corresponding author: Michael Ezersky, E-mail: mikhail@gii.co.il, Tel: +972-8-978 5865 
estimation of the site transfer amplification factor. However its use in regions with relatively low seismic activity like in Israel is usually impractical.

Finally, the third group is a practical and low cost tool and is becoming more and more popular over the last decades (Kagami et al 1982, Yamanaka et al 1994). It offers a convenient technique, especially through urbanized areas.

In the last decade, the Geophysical Institute of Israel (GII) used H/V spectral ratios from ambient noise (HVSR) supplemented with on-site geophysical, borehole and geological information to derive the required models of the subsurface. Part of the information (Vs profile) is usually obtained from S-wave seismic refraction surveys (Palmer 1986). However, use of the latter is often hampered by problems in generating $\mathrm{S}$-waves because of weak source and the difficulties in performing a geophysical survey in urban areas. Another method allowing constructing the subsurface Vs profile is the widely used Multichannel Analysis of Surface Waves (MASW). The MASW technique is based on the study of the dispersion of surface waves (Park et al 1999). Since a surface wave is frequency dependent, i.e. dispersive, the Vs structure can be obtained by inversion of surface-waves dispersion curves (Xia et al 1999). Depending on how the surface waves are generated, active and passive MASW techniques can be known (Park et al 2007). The passive MASW is based on measurements of ambient noise (tidal motion, sea waves, wind, traffic, industry activities). In most cases, passive MASW method is combined with its active modification when excitation of surface waves is performed using a sledgehammer and other active seismic sources (like dropping weight, for instance) (Park et al 2005).

The MASW method was largely developed taking into account recommendations of the National Earthquake Hazard Reduction Program (NEHRP) about site classification averaging shear-wave velocity (Vs) over 30 m (BSSC 1994). Therefore, the MASW conventionally uses 4.5 $\mathrm{Hz}$ geophones and the penetration depth of surface waves is restricted (usually, by uppermost $30 \mathrm{~m}$ ) because of frequency (wavelength) limitations (Park 2006).
Boor et al (1997) note that use of average shear-wave velocity to a depth of $30 \mathrm{~m}$ as a variable to characterize site conditions is a choice dictated by the relative unavailability of velocity data for greater depths, and it is necessary to develop deeper estimates of Vs. That is why one of the objectives of this study is modifying the MASW method to increase penetration depth.

In addition, Zaslavsky et al (2012), based on synthetic acceleration response spectra of real sites, conclude that a single parameter $\mathrm{Vs}_{30}$ cannot be used for generalizing site classification in the complex geological conditions of Israel.

The main goal of this study is to combine H/V spectral ratio from ambient noise (HVSR method) with the modified MASW technique to obtain reliable shear-wave velocity structure of the subsurface down to bedrock. Similar combination of techniques is reported for the first time in seismological literature by Scherbaum et al (2003). This combination allows deriving quantitative information on $\mathrm{S}$-wave velocity sections for the study site and enables investigating deep properties of the medium. The main objectives are as follows:

- Modifying the MASW method to increase the penetration depth and resolution,

- Applying the improved MASW method in its active (passive, combined) modes to construct shear-wave velocity (Vs) profile,

- Evaluating 1-D subsurface models via fitting an analytical transfer function, using SHAKE code to an observed HVSR and taking into account Vs-depth profile from MASW measurements and available geotechnical and geological data as constraints,

- Testing combination of HVSR and MASW methods in different geological conditions.

\section{P- and S-wave velocities in soils and rocks of Israel}

Shear-wave velocity measurements are an important tool in designing buildings for site specific conditions such as soil liquefaction, ground-spectral earth quake response, etc. Being slightly dependent on soil saturation, shear-wave velocities are much more of a diagnostic tool for 
engineering properties than P-wave ones. Seismically, shear-wave velocity $(V s)$ is the best indicator of shear modulus that is directly linked to a material's stiffness and is one of the most critical engineering parameters. There are several methods of Vs measurements in laboratory and in-situ conditions.

In situ geophysical methods include borehole and surface measurements. The most accurate method is the cross-hole one (ASTM D4428/D4428M, 1991 (1995)). This method requires at least 2 highly parallel boreholes and is limited to a depth of $30 \mathrm{~m}$. Another method is the downhole one (ASTM D7400, 2007) allowing Vs measurement of a single borehole. The borehole is encased by a PVC pipe or filled with bentonite to stabilize the borehole walls. In the first case, measurements can be affected by the quality of the borehole walls and fill geometry. In addition soil characteristics in borehole can differ from those in the site located $100 \mathrm{~m}$ away.

Surface methods of measurements include seismic refraction measurements (Palmer 1986)

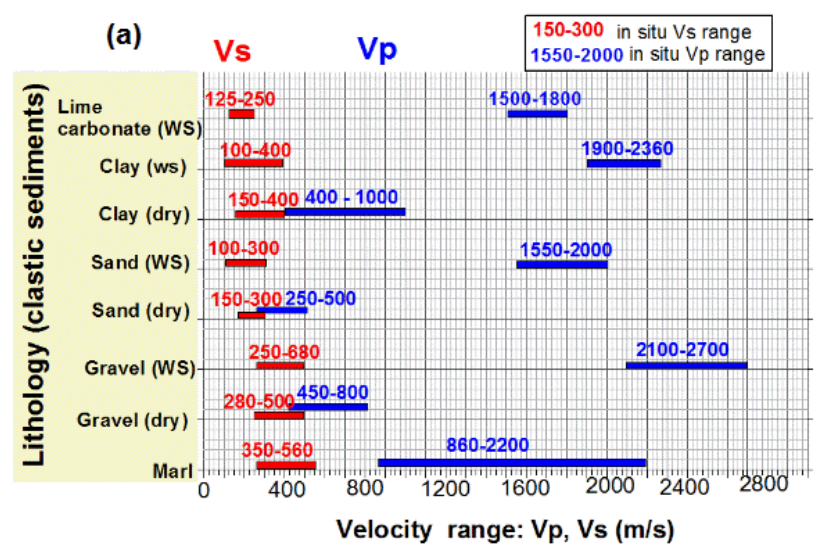

and Surface Wave prospecting (SWP) methods (Park et al 1999, Socco and Strobia 2004, Stokoe II et al 2006). If refraction method is based on direct S-wave excitation and measurements, SWP method is based on the nature of Rayleigh waves whose phase velocity depends on Vs and its distribution with depth. Latter waves are of dispersive origin that testifies possibility to penetrate to different depths. Although methods like shear-wave refraction, downhole, and crosshole surveys can be used, they are generally less economical than SWP in terms of field operation, data analysis, and overall cost. Multichannel Analysis of surface Waves (MASW) is one of SWP techniques.

Numerous surveys carried out in Israel allow estimating the range of seismic compression wave (Vp) and shear-wave (Vs) velocities of the sediments and rocks down to a depth of $100 \mathrm{~m}$. The schema characterizing ranges of in-situ seismic velocities in the soils and rocks of Israel is presented in Figs. 1a and 1b, respectively.

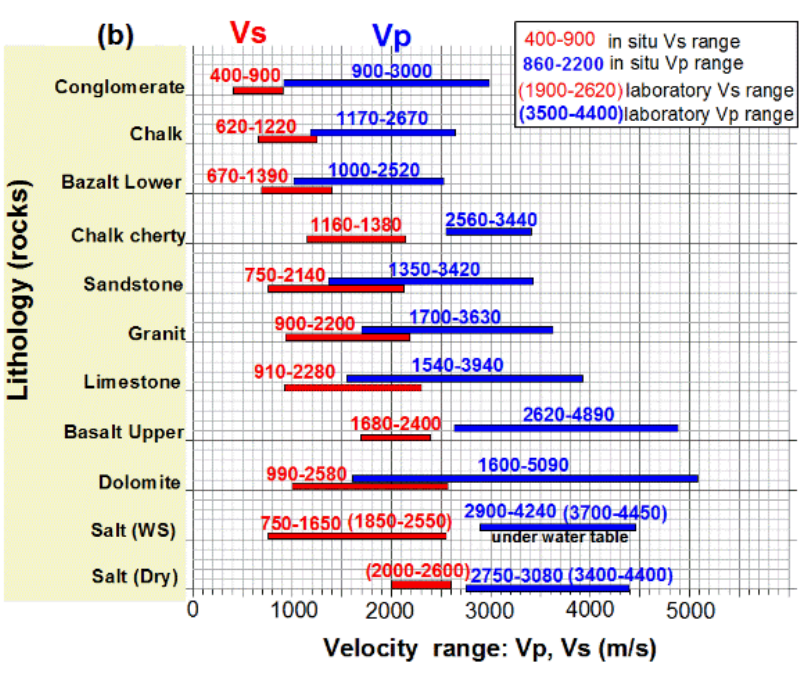

Fig. 1 Range of Vp and Vs in soils (a) and rocks (b) measured in Israel in-situ and in laboratory (in brackets) conditions

Analysis of Figs. 1a and $1 \mathrm{~b}$ allows us to conclude that ranges of both $\mathrm{Vp}$ and Vs seismic velocities in soils and rocks generally conform to those measured by other researchers in shallow subsurface (Jakosky 1957). However, Vp values in rocks reported in literature are higher (for instance, $\mathrm{Vp}=5800 \mathrm{~m} / \mathrm{s}$ in granite, $\mathrm{Vp}=6100$ $\mathrm{m} / \mathrm{s}$ in limestone) than those measured in Israel.
The higher Vp values could be explained by the high stress and better rock quality in deep measurement conditions. Shear-wave velocities measured throughout Israel vary by a wide range: from $100 \mathrm{~m} / \mathrm{s}$ in sands and lime carbonates to more than $600 \mathrm{~m} / \mathrm{s}$ in gravels, and from $400 \mathrm{~m} / \mathrm{s}$ in conglomerates to more than $2400 \mathrm{~m} / \mathrm{s}$ in basalts and dolomites. Variability of $\mathrm{Vs}$ and 
thickness of soft sediments overlying hard rock on the one side, and very limited availability of densely distributed geotechnical information such as Vs at depth call for less expensive and less time consuming methods to provide the required parameters for site effect assessment. Data presented in Figs. 1a and 1b allow consideration of approximate range of Israeli sediments and rocks for preliminary evaluation of possible site response and modeling. Separately, we consider velocities in the salt constituting firm layers along the Dead Sea coastal area.

\section{Methods}

\subsection{HVSR method}

\subsubsection{General}

Nakamura (1989) hypothesized that site response could be estimated from the spectral ratio of horizontal versus vertical components of noise observed at the same site (site of interest).

The HVSR technique has become the primary tool of choice in many of the ambient noise related studies and it has been successful in seismology to estimate the local transfer function in the site response problem in Israel and worldwide (Lerma and Chávez-García 1994, Malischewsky et al 2010, Mucciarelli and Gallipoli 2004, Seekins et al 1996, Zaslavsky et al 2005, 2008, 2009). Nakamura's method is based on the assumption that micro-tremors consist of body waves. Mucciarelli and Gallipoli (2004) claimed that the H/V spectrum of ambient noise is dominated by the upward propagation of $\mathrm{SH}$ wave through the layered media. On the other hand, an explanation based on the opposite assumption that micro-tremors mainly consist of surface (Rayleigh) waves is also successful (e.g. Fäh et al 2001, Lachet and Bard 1994). Both models agree that the $\mathrm{H} / \mathrm{V}$ spectra and the site response function for $\mathrm{SH}$ wave are the results of the velocity structure of the media, that both exhibit the same fundamental resonance frequencies with similar amplitudes at least when considering small motions. Malischewsky and Scherbaum (2004) demonstrated analytically the coincidence of $\mathrm{H} / \mathrm{V}$ from the ellipticity of Rayleigh waves and the fundamental frequency for higher impedance contrasts (by a factor of 4).

It was demonstrated through many studies (Zaslavsky et al 2005, 2008, 2009) that, when noise measurements are made near boreholes and/or near refraction surveys, the fundamental frequency and its corresponding $\mathrm{H} / \mathrm{V}$ amplitude are practically the same as the fundamental frequency and its corresponding amplification level derived from the computed transfer function of SH-waves at low strains propagating through a relatively simple 1-D model of the site, as known from geotechnical and geophysical surveying. Computer code SHAKE (Schnabel et al 1972) is used to analytically evaluate the site response function. The specific parameters required for this analysis are:

- S-wave velocity, thickness, density and damping of each layer in unconsolidated sediments, and

- S-wave and density of the hard rock (reflector).

\subsubsection{HVSR data acquisition}

The methodology of HVSR data acquisition and processing was presented in details in Zaslavsky, et al. (2009). Ambient noise measurements were made using portable instruments (Shapira and Avirav 1995) consisting of a multi-channel amplifier, a Global Positioning System (GPS) for timing, and a laptop computer with a 16-bit analogue-to-digital conversion card to digitize and store the data. Each seismograph station consists of three (one vertical and two horizontal) L4C velocity transducers (Mark Products) with a natural frequency of $1.0 \mathrm{~Hz}$ and damping ratio $65-67 \%$ of critical. The sample rate was 100 samples per second and filter band-pass was between $0.2 \mathrm{~Hz}$ and $25 \mathrm{~Hz}$. All the equipment: sensors, power supply, amplifiers, personal computer, and connectors were portable allowing performing of measurements in autonomous mode.

\subsubsection{HVSR data processing}

For each site, the average $\mathrm{H} / \mathrm{V}$ spectral ratios and their corresponding standard deviations were determined by applying the following process: time windows, each of 30-60 seconds long depending on fundamental frequency. The 
selected time windows were Fourier transformed, using cosine-tapering (1 second at each end) before transformation and then smoothed with a triangular moving Hanning window. The H/V spectral ratios were obtained by dividing the individual spectrum of each of the horizontal components by the spectrum of the vertical component. To obtain consistent results from the spectra of ambient noise, 60-70 time windows were used and then averaged with the spectral ratios. Data processing was carried out using "SEISPECT" software developed in the Geophysical Institute of Israel (Perelman and Zaslavsky 2001).

\subsection{MASW method}

\subsubsection{General}

Surface-wave dispersion inversion (SWDI) is a standard approach for inferring a 1D Vs structure. Surface waves, commonly known as ground roll, are always generated in all seismic surveys, have the strongest energy, and their propagation velocities are mainly determined by the medium's shear-wave velocity.

The development of multichannel equipment has led to exploiting the methodology known as Multichannel Analysis of Surface Waves (MASW) (Park et al 1999, Xia et al 1999). The MASW method is basically an engineering seismic method dealing with frequencies mainly 3-30 Hz recorded by using a multichannel (24 or more channels) recording system and a receiver array deployed over a 2-200 $\mathrm{m}$ distance. The active MASW method generates surface waves actively through an impact source like a sledge hammer, whereas the passive method utilizes surface waves generated passively by cultural (e.g. traffic) or natural (e.g. thunder and tidal motion) activities (Park et al 2007).

Active MASW. Active-source surface-wavedispersion measurements are made with typical seismic shot gatherers that are a collection of seismic traces, which share some common geometric features. The wave field is transformed into a frequency-wave number (or frequencyslowness) domain in which the maxima should correspond to surface-wave signatures. Several modes can be picked out for such dispersion curves if the propagation mode signatures are well separated. The dispersion curves are then inverted for a 1D Vs profile with depth. When data are collected in a roll-along mode, each 1D profile is represented at its corresponding midpoint spread, allowing a pseudo-2D Vs section to be drawn. The inverse problem formulation imposes that the investigated medium is assumed as one-dimensional under the spread. Long spreads are required to record wavelengths large enough for increasing the investigation depth and mitigating near-field effects (Bodet et al 2005, Socco et al 2009).

Passive $M A S W$. The passive surface waves generated from natural (e.g. tidal motion) or cultural (e.g. traffic) sources are usually of a lowfrequency nature with wavelengths ranging from a few kilometers (natural sources) to a few tens (or hundreds) of meters (cultural) (Okada 2003), providing a wide range of penetration depths and therefore a strong motivation to utilize them. The ambient noises are recorded using receiver arrays (antennae) arranged as different geometrical figures (linear, circular, cross layout, etc.). The most accurate estimation is obtained through a survey using a true $2 \mathrm{D}$ receiver array (Park and Miller 2006). However, because the true 2D receiver array, such as a circular and cross-layout ones are not a practical or possible mode of survey in built-up urban areas, a method that can be implemented with the conventional 1D linear receiver array can be effective in this case (Louie 2001). The data processing scheme can be found in Park et al. (2007).

Combination of active and passive MASW measurements. Dispersion images processed from active and passive data sets should be combined to obtain improved dispersion curves. The active MASW method generates signals in about $30 \mathrm{~Hz}$, whereas the passive one allows for widening that to the low frequency range down to geophone frequency. Combining two signals, we widen the range of frequencies from $3-30 \mathrm{~Hz}$, and sometime even up to $50 \mathrm{~Hz}$. Thus, the penetration depth can be increased to a deep range (low frequencies) and the uppermost depth can be decreased (high frequencies) (Park et al 2007). 


\subsubsection{Data acquisition}

\subsubsection{Practical aspects of data acquisition}

Although methods like shear-wave refraction, downhole, and cross-hole surveys can be used, they are generally less economical than any other seismic methods in terms of field operation, data analysis, and overall cost. The great advantage of the surface wave method in comparison with the

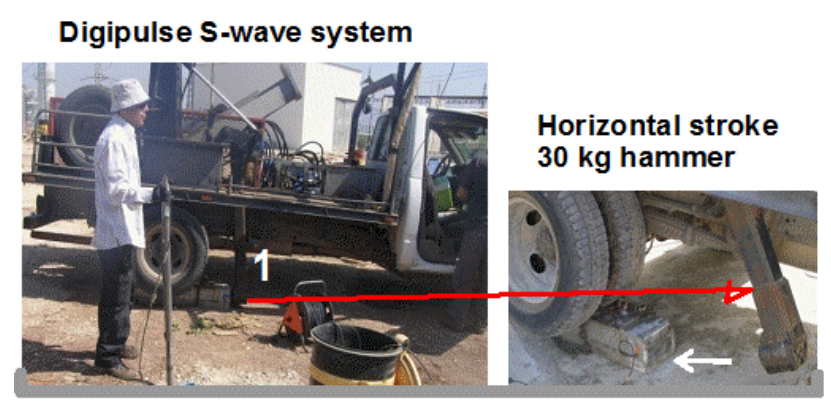

a

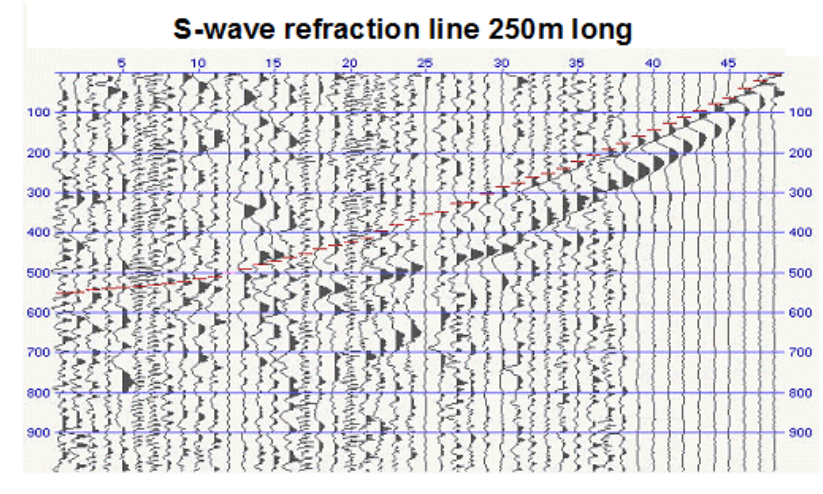

c refraction one is the quality of the field records. We illustrate it comparing two above acquisition methods in Fig. 2. Surveys were carried out along the same length line by different hammers. The data acquisition of S-waves with the refraction method was carried out using the horizontal stroke of a $30 \mathrm{~kg}$ sledge hammer (Fig. 2a) allowing a most clear excitation of $\mathrm{SH}$ waves at the background of other waves.

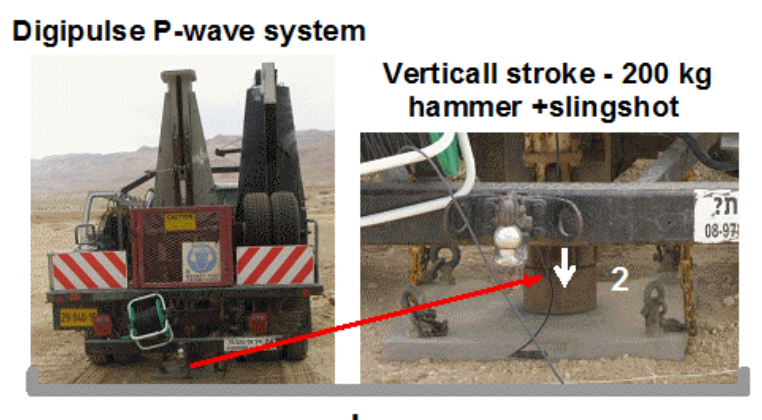

b

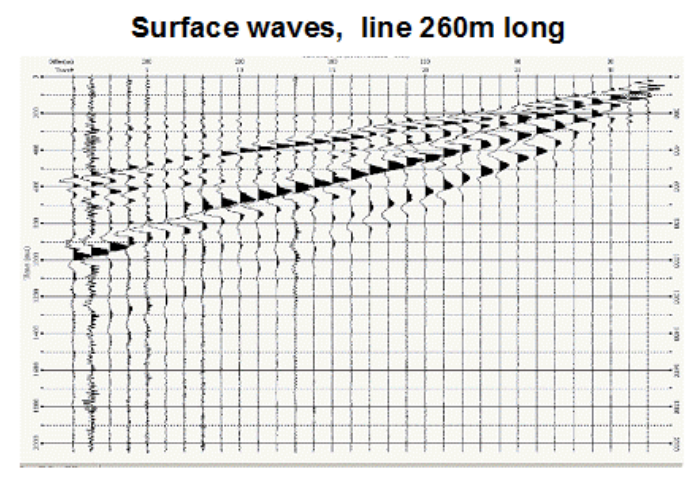

d

Fig. 2 Comparison of seismic methods for S-wave acquisition. (a) Excitation of S-waves in the seismic refraction technique using horizontal stroke on metallic beam by a $30 \mathrm{~kg}$ hammer; (b) raw data obtained at such stroke complicated by strong noise; (c) excitation of surface wave of R (Rayleigh) type using vertical stroke by a $200 \mathrm{~kg}$ hammer forced by slingshot; and (d) field records of surface waves

However, because of weak source, S-wave records are complicated by ambient noise (Fig. 2b) allowing penetration of $\mathrm{S}$-wave as a rule to 25-30 m. On the other hand, surface waves, because of strong vertical stroke by the $200 \mathrm{~kg}$ hammer (in our case, forced by slingshot) (Fig. $2 \mathrm{c}$ ), are characterized by the strongest energy, and their propagation velocities are mainly determined by the medium's shear-wave velocity. The quality of the field records is significantly higher (Fig. 2d) and allows penetration down to depths determined by wavelength (that is usually some tens to hundreds of meters).

\subsubsection{Modified data acquisition}

Active MASW. Conventional seismic data (i.e. the vertical component of the wave field from common shot records obtained in shallow refraction surveys) were used. To increase penetration depth of surface waves, we used vertical low frequency $2.5 \mathrm{~Hz}$ geophones implemented to seismic profile. Receiver spacing was varied with respect to necessary penetration depth from 2.5-10 m; shot location was 5-10 m away from nearest trace (off-end shooting). Data excitation was carried out using power Digipulse hydraulic source mounted on a Chevrolet pickup 
truck (Fig. 2). Both geophone frequency and power source facilitate recording raw data of high quality and more penetration depth. A Summit II plus seismic recorder was used with a 24-48 geophone spread (vertical $2.5 \mathrm{~Hz}$ geophones). The number of geophones as well as line length selected in accordance with the depth of target.

At first, P-wave seismic refraction study was carried out along study line using $2.5 \mathrm{~Hz}$ vertical geophones. Record length for P-wave refraction was $500 \mathrm{~ms}$. Then record length was increased to $2000 \mathrm{~ms}$ and surface waves were recorded.

Passive MASW. Passive MASW measurements were carried out using linear system located along the roads (roadside schema) with $2.5 \mathrm{~Hz}$ geophone separation of $5 \mathrm{~m}$. Other array used in Israel was circular array with 5-10 $\mathrm{m}$ separation between geophones (Ezersky et al 2013b).

Then active and passive records were combined using SurfSeis v3 software.

\subsubsection{Data processing}

Data processing is applied to (a) P-wave refraction data, and (b) surface wave data.

a) P-wave refraction processing is intended for constructing $\mathrm{Vp}$ depth layered model and determination depth to firm layer (reflector). These data are used for generating of initial model for surface wave inversion.

b) Surface wave data are used for: (1) generation of dispersion image, (2) extraction of dispersion curve, and (3) its inversion. All these were carried out using SurfSeis v3. Software of Kansas Geological survey (KGS). This software allows any combination of active and passive dispersion images with different parameters of measurements (different frequency, separation of geophones, etc.).

An inversion of the dispersion data was carried out using linearized inversion with a gradient-based iterative method (Park et al 1999, Xia et al 1999) implemented to above mentioned software. The Root Mean Square Error (R.M.S.E.) between the theoretical dispersion curve and the measured one is usually used as an indicator of the closeness between measured and iteratively calculated dispersion curves. Usually, in linearized inversion methods, constraints are applied to the solution in order to reduce the degree of non-uniqueness. Constraints are data available from independent geological and geophysical information, such as longitudinal (compression) wave velocity ( $\mathrm{Vp})$, depth to reflector layer or half space, firm layer thickness and composition, geological section of the site under investigation. These data are intended to confine result of inversion by possible parameters. The dispersion equation depends mainly on Vs, and thickness value in the layers. An appropriate choice of these parameters (the initial model) is considered as a fundamental issue for the successful application of inversion (Socco and Strobia 2004).

The most important part of the MASW data processing is constructing an initial layered model for inversion. Generally, bounds of wave velocities are presented in Fig. 1. Some parameters can be selected using well-known rules of thumb (Xia et al 2003): (a) Vp versus Vs ratio can be considered bounded for near surface materials, assuming Poisson's ratio, with values ranging from 0.20 to 0.48 , and (b) The Rayleighwave velocity is 0.92 of $\mathrm{Vs}$ in an uniform halfspace (for Poisson's Ratio of 0.25). As a reference model for inversion, Vs can be approximated by the phase velocity multiplied by a correction factor (less than unity for fundamental-mode data). The examples of field records and data processing will be considered in continuation.

Inversion was carried out at constant $\mathrm{Vp}$ values, whereas Poisson's Ratio varied (Ezersky et al 2013a). Such inversion procedure allows stabilizing the inversion results.

\subsection{Combination of HVSR and MASW methods}

Data collected from a few seismic profiles provide information on the S-wave velocities and thickness of shallow sediments (down to 50-100 $\mathrm{m})$ within the accuracy and resolution of the geophysical technique. Seismic MASW profiles are normally designed to obtain maximum information on Vs of the lithological units represented in the study area and in the vicinity of boreholes. Measurements of ambient vibrations were also carried out either very close to or 
directly at drilling sites where detailed information on the subsurface was available. The logging data are incorporated to obtain more detailed and reliable information about the subsurface. Then, the borehole and geophysical information were combined with the observed spectral ratios to estimate the depth $\mathrm{S}$-wave velocity profile. The iterative procedure based on the stochastic optimization algorithm (Storn and Price 1995) was applied in order to fit an analytical transfer function, estimated using SHAKE code (Schnabel et al 1972) to an observed $\mathrm{H} / \mathrm{V}$ spectral ratio, focusing mainly on the resonance frequencies and considering the shape of $\mathrm{H} / \mathrm{V}$ curve. Thus, combining the borehole and geophysical information with the observed spectral ratios 1-D the depth - Vs velocity profile was derived.

\subsection{Resolution of MASW method}

The resolution of MASW method is considered usually as a rule of thumb (Bodet et al 2005, Richart et al 1970, Park et al 1999, O’Neill 2003, Shtivelman 1999). Many conclusions are based on experimental results. Some issues should be considered here in this context: (1) maximum and minimum penetration depth, (2) their relationships with seismic line length, and (3) reliability of measured velocities. The resume is based on literature data and our experience (Ezersky et al 2013a, 2013b).

Maximum penetration depth. At the beginning of our study, we checked the main concerns and possibilities for increasing penetration depth. The normally accepted axiom (Richart et al 1970) is that the penetration depth $\left(Z_{\max }\right)$ of ground roll is approximately equal to its wavelength $(\lambda)$ and may be up to $2 \lambda$. Then the question arises, what is the maximum penetration depth $\left(Z_{\max }\right)$ for which $V_{S}$ can be reasonably (exactly enough) calculated. Park et al. (1999) evaluate it as $0.5 \lambda_{\max }$. Rix and Leipski (1991) evaluate it as (0.5-1.0) $\lambda_{\max }$. The maximum depth depends on the maximum reliably estimated wavelength. Different authors suggest $Z_{\max }$ as a rule of thumb. Some estimations have been suggested. As a rule, it is estimated as $0.25 \lambda_{\max }$ (Bodet et al 2005),
$0.5 \lambda_{\max }$ (Shtivelman 1999) to (0.5-1) $\lambda_{\max }$ (Rix and Leipski 1991). The latter affirms that the best overall accuracy and resolution would be obtained when the dispersion data is evenly distributed between the minimum and maximum wavelengths and the maximum wavelength is one to two times the maximum desired depth of the shear-wave velocity profile.

It is important to note that in principle, penetration depth can reach $\lambda_{\max }$ (and even, more). It depends on some factors such as shear-wave velocity of overburden, frequency, and signal quality. Our experience (Ezersky et al 2013a) shows that in most cases (with $2.5 \mathrm{~Hz}$ geophones) criterion of $Z_{\text {max }}=0.5 \lambda_{\max }$ is enough to estimate properties (Vs) of the foundation down to 40-60 $\mathrm{m}$ depth. However, in rare cases deeper reflector penetration depth should be checked as an exception. Example of such a case is presented here for Ramat Hakovesh site described in this article, where active and passive MASW measurements were carried out:

$$
\begin{aligned}
& V_{p h_{\text {max }}}=708 \mathrm{~m} / \mathrm{s} \\
& f_{\text {min }}=2.96 \mathrm{~Hz} \\
& \lambda_{\text {max }}=V_{p h_{\text {max }}} / f_{\text {min }}=239 \mathrm{~m}
\end{aligned}
$$

Where, $f_{\min }=$ minimum frequency measured in combined image, $V_{p h}$ max $=$ maximum phase velocity, measured at this frequency, and $\lambda_{\text {max }}=$ maximum wavelength. Thus, we can accept the criterion of Rix and Leipski (1991) that maximum penetration depth can be evaluated as between 120 and $239 \mathrm{~m}$. However, it is reasonably to accept maximum penetration depth as $120 \mathrm{~m}$ at least.

Relationship between $\lambda_{\max }$ and length of geophone line (array). This issue is debated by different investigators. It is generally considered that length of receiver spread (L) is directly related to the longest wavelength $\left(\lambda_{\max }\right)$ that can be analyzed, e.g. $L \approx \lambda_{\max }$ (Park et al 1999). $L=X_{1} *(N-1)$, where $X_{1}$ is separation between geophones and $\mathrm{N}$ is number of geophones in spread. Parameter $X_{1}=H_{1}$ is connected with a 
minimum measured depth in limits of which Vs can be considered as a reliable value (Stokoe et al 1994), e.g. $H_{1}>0.5 \lambda_{\text {min }}=0.5 V_{p h_{\text {min }}} / f_{\text {max }}$, where $f_{\max }$ is the highest frequency at which minimum phase velocity $V_{p h_{\min }}$ can be measured. Socco and Strobia (2004) concluded that really, wavelengths longer than the array could be observed, and the maximum wavelength depended mainly on the quality of the dispersion image. Our experience shows the correctness of this conclusion.

Our concept is to use frequencies as low as possible to reach a maximum penetration depth. To improve quality of signal ( $\mathrm{S} / \mathrm{N}$ ratio) we have used in Israel: (1) low frequency geophones, (2) power Digipulse source based on Chevrolet pickup truck (Fig. 2b), (3) long seismic line, and (4) all available information (borehole data, refraction seismic and TEM measurement).

The increase in penetration depth is reached also by a combination of active and passive sources (Park et al 2007). That is why we also consider (0.5-1.0) $\lambda_{\max }$ criterion as determining $Z_{\text {max }}$ suggested by Rix and Leipski (1991). This criterion well corresponds to our conditions and data. We have checked it with passive MASW, which has a penetration depth $Z_{\max }>0.5 \lambda_{\max }$.

Resolution in uppermost subsurface. The thickness $H_{1}$ of the uppermost (irresolvable) layer limiting the resolution of sub-surfaces is determined by the wavelength and parameters of the data acquisition system according to the halfwavelength criterion (Rix and Leipski 1991). The normally accepted criterion is that the minimum penetration $H_{1}$ is determined by (Stokoe et al 1994):

$$
H_{1} \geq 0.5 \lambda_{\min }=0.5 V_{p h_{\min }} / f_{\max }
$$

where $V_{p h_{\min }}$ is the minimum phase velocity of the fundamental mode and $f_{\max }$ is corresponding frequencies at the phase velocity measured.

The problem can be resolved in two ways. The first way is to vary the geophone separation at active MASW. The second way is to use high frequency array. The real example of data acquisition with separations of $10 \mathrm{~m}$ and $2.5 \mathrm{~m}$ (both, $2.5 \mathrm{~Hz}$ geophones) and separation of $5 \mathrm{~m}$ and $10 \mathrm{~Hz}$ geophones show:

$2.5 \mathrm{~Hz}$ geophones, $10 \mathrm{~m}$ apart:

$$
\begin{aligned}
& V_{p h_{\min }}=219 \mathrm{~m} / \mathrm{s} \\
& f_{\max }=15 \mathrm{~Hz} \\
& H_{1}=\lambda_{\text {min }} / 2=7.3 \mathrm{~m}
\end{aligned}
$$

$2.5 \mathrm{~Hz}$ geophones, $2.5 \mathrm{~m}$ apart:

$$
\begin{aligned}
& V_{p h_{\text {min }}}=219 \mathrm{~m} / \mathrm{s} \\
& f_{\text {max }}=23 \mathrm{~Hz} \\
& H_{1}=\lambda_{\text {min }} / 2=4.7 \mathrm{~m}
\end{aligned}
$$

$10 \mathrm{~Hz}$ geophones, $5 \mathrm{~m}$ apart:

$$
\begin{aligned}
& V_{p h_{\text {min }}}=256 \mathrm{~m} / \mathrm{s} \\
& f_{\text {max }}=59 \mathrm{~Hz} \\
& H_{1}=\lambda_{\text {min }} / 2=2.2 \mathrm{~m}
\end{aligned}
$$

It is clearly seen that a more effective way to improve the resolution of MASW at small depth is to increase geophone frequency instead of decreasing separation.

\section{Parametric study}

Within the framework of this paper, we consider two typical subsurface structures forming conditions for site effect (Fig. 3).

In the first model, one or two hard layers are over- and underlain and by soft soil ("Layer model"). This case is presented by salt layers of 5-30 m thickness located at a depth of 20-50 m along the Dead Sea coast that is a national and international resort area. The subsurface structure in the second case is widespread in the Israel plain, and is formed by soft sediments overlaying rigid rock ("Half-space model"). With respect to the surface waves prospecting method, the penetration depth depends on geophone frequency used. Forward modeling carried out for the two above models of subsurface (Fig. 3b dashed and solid lines) has shown that dispersion curves are significantly differed (dashed and solid graphs in Fig. 3a, respectively). Fig. 4 shows 
examples of two combined dispersion images obtained in subsurface of above structure.

Usually, geophones of $4.5 \mathrm{~Hz}$ are mainly used for surface-wave prospecting. Fig. 3a shows that in the frequency range of more than $5.5-6 \mathrm{~Hz}$ both curves are non-distinguishable. To distinguish between recorded curves frequency should reach the frequency range between 4.5-6 Hz. As a rule, to obtain such frequency the source should be powerful.

Otherwise, surface waves cannot penetrate overburden. Geophones used in our study $(2.5 \mathrm{~Hz})$ together with power Digipulse source allowed low frequencies down to $2.5 \mathrm{~Hz}$ (Fig. 4a). These (together with proper line long) allow penetration of both overburden and solid layers down to a depth of 70-100 m and even more (Ezersky et al 2013a, 2013b). Thus, the MASW method in our modification allows for resolving the objectives formulated in Section 1.

\section{Testing combination of HVSR and MASW methods at two sites of Israel}

\subsection{North of the Dead Sea}

\subsubsection{Ein Boqeq site}

The Ein Boqeq area, 1.5-2.0 km long and 250$300 \mathrm{~m}$ wide, extends along the southern Dead Sea (DS) basin (recently evaporation ponds were artificially filled by pumping DS water from the northern basin (site EB in Fig. 5a). Several hotels

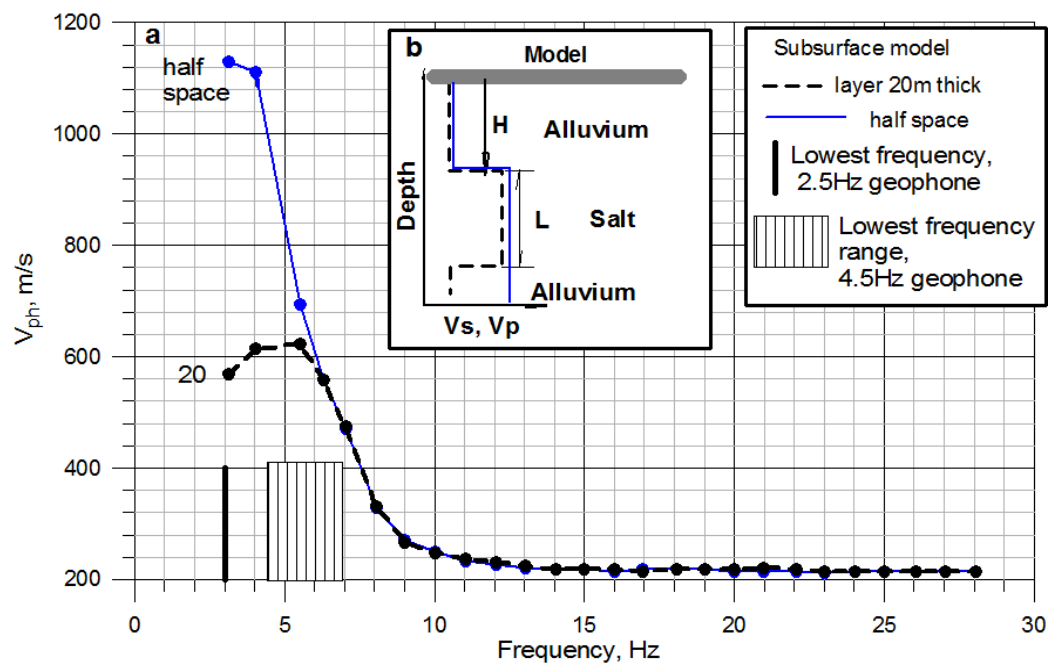

Fig. 3 Forward modeling. (a) Two dispersion curves corresponding to subsurface models shown in (b). Dashed line corresponds to firm salt layer of $20 \mathrm{~m}$ thickness located under alluvial sediments at a depth of $25 \mathrm{~m}$. Salt layer is also underlain by alluvial sediments; Salt velocity Vs is $1650 \mathrm{~m} / \mathrm{s}$. Solid graph corresponds to the rigid half space (rock) overlain by alluvial sediments. Vs of half space is also $1650 \mathrm{~m} / \mathrm{s}$

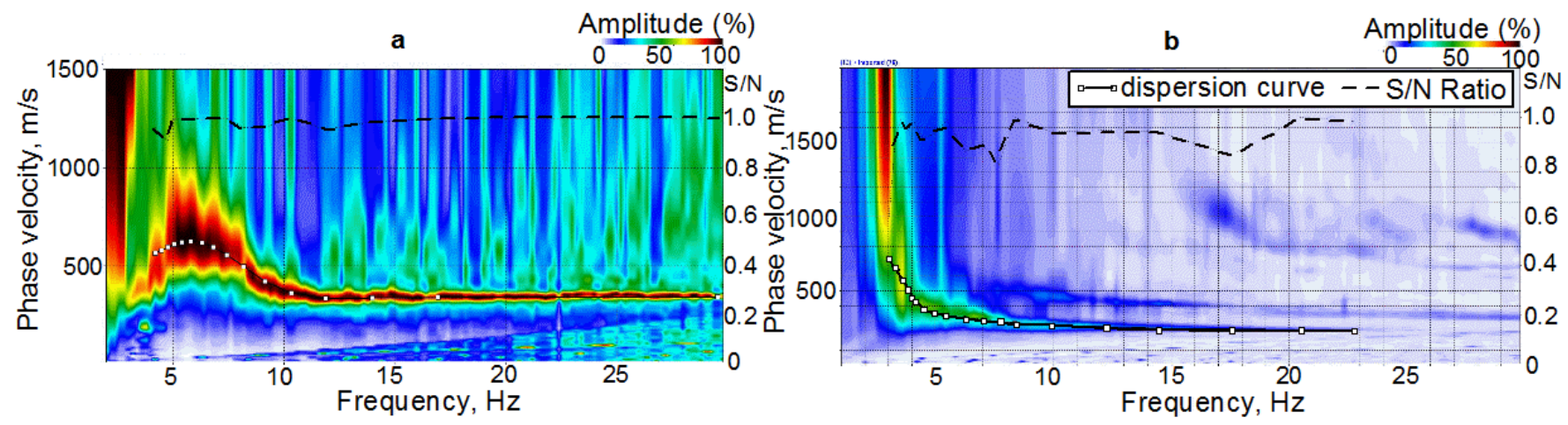

Fig. 4 Examples of combined dispersion images with extracted dispersion curves for subsurface models discussed above. (a) Ein Boqeq site - "Layer model" (dashed line in Fig. 3b); (b) Ramat Hakovesh site - the "Half space" (solid line in Fig. 3b) is located at a depth of $74 \mathrm{~m}$ deep under alluvial sediments. In both cases the dark zone near $2.5 \mathrm{~Hz}$ is an anomaly associated with maximum energy near resonant frequency 

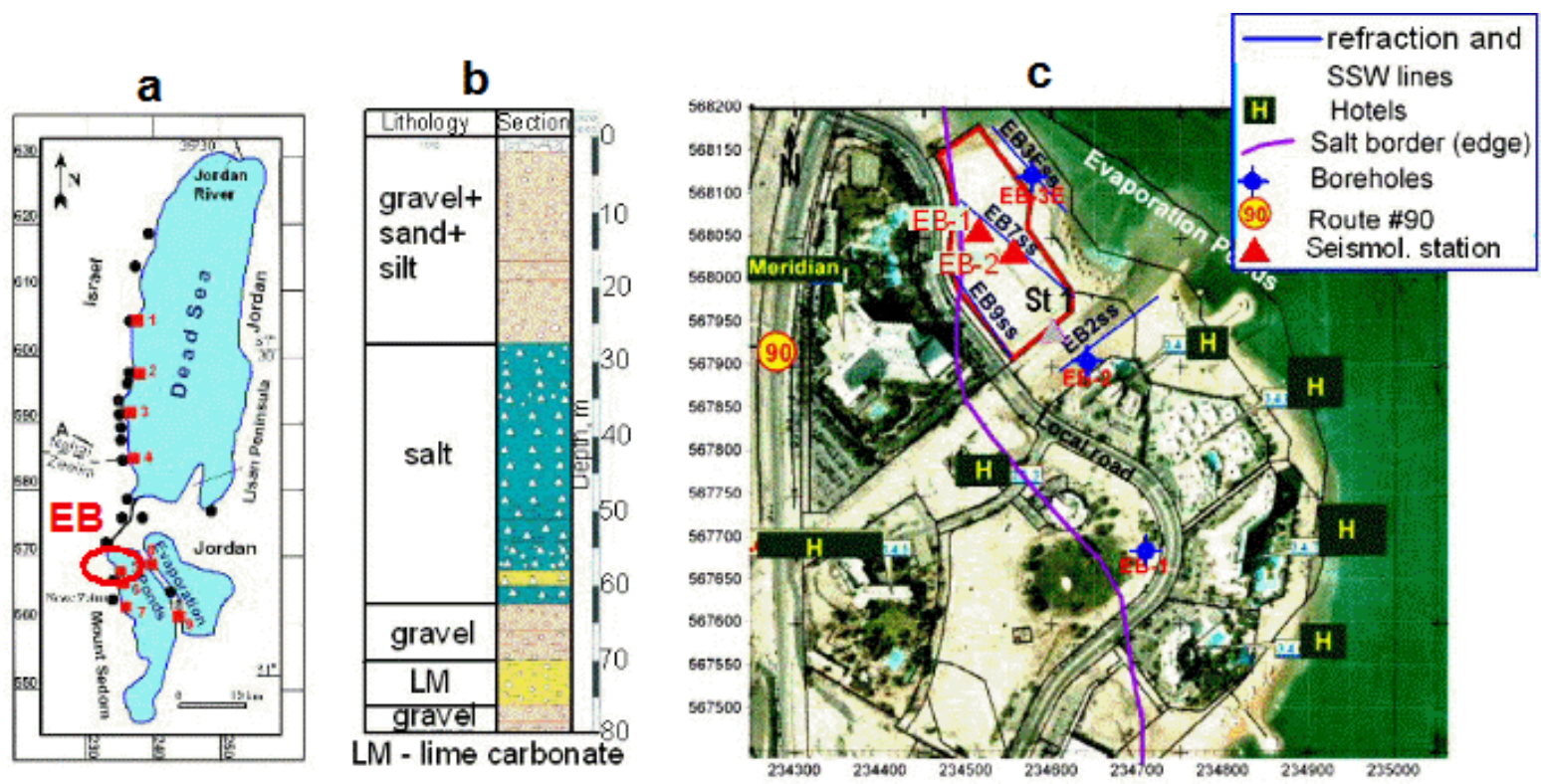

Fig. 5 Ein Boqeq north site. (a) Site location map, (b) EB-2 borehole section (after Yechieli et al 2004), and (c) Geophysical measurements layout

are located in Ein Boqeq, which is also named the Hotel area. The study area is situated in the northern part of Ein Boqeq, about 2-3 km east of the Judea Mountains (see Fig. 5a and 5c). According to data of boreholes EB-1 and EB-2 (Yechieli et al 2004), geological section of this area is represented by pebbles, cobbles and siltysandy sediments (Fig. 5b). Borehole EB-3E crossed a sandy-gravel alluvium layer overlying the salt unit at $26 \mathrm{~m}$ deep. At a depth of $32 \mathrm{~m}$, borehole met crushed salt and at $35 \mathrm{~m}$, deep drilling was stopped. The sediments revealed by EB-3E borehole conform to those from boreholes EB-1 and EB-2 located some 200-400 m south of the study site. The thickness of the salt unit is 28 $\mathrm{m}$.

\subsubsection{MASW measurement results}

Passive MASW measurements. Passive MASW measurements were carried out using a roadside technique along a 24-channel line located south of the Hod Hotel, 35-45 m away from a local road (Fig. 6a).

An example of ambient noise record from traffic is shown in Fig. 6b. Noise was recorded during 1 minute with a sample rate of $4 \mathrm{~ms}$. The dispersion image with the extracted dispersion curve is depicted in Fig. 6c. The frequency range is between 2.5 and $12 \mathrm{~Hz}$.

Active MASW measurements. Results of active MASW measurements along Line 7ss (see Fig.5c for location) are shown in Fig. 7. Active signal is of a good quality (Fig. 7a) that allows extraction of dispersion image of a good quality ( $\mathrm{S} / \mathrm{N}$ Ratio is in limits of 1.0-0.9) in a wide frequency range between $5-30 \mathrm{~Hz}$ (Fig. 7b).

Combined MASW measurements. Combined image shown in Fig. 4a integrates the dispersion images of passive and active MASW surveys presented in Figs. $6 \mathrm{c}$ and $7 \mathrm{~b}$, respectively. The refraction P-wave depth velocity section used as constraint for inversion is shown in Fig. 8a. Combined inversion of the dispersion curve for 5 layered model is presented in Fig. 8b (R.M.S.E. $=12 \%$ ) and in Table 1. The depth to the top of salt layer is accepted as $26 \mathrm{~m}$.

\subsubsection{HVSR measurement results}

Ambient noise measurements were carried out close to borehole EB-2 (see Fig. 5c for location). Individual and average $\mathrm{H} / \mathrm{V}$ spectral ratios obtained at station EB-2 are shown in Fig. 9a.

Two prominent resonance peaks observed at a frequency of $0.65 \mathrm{~Hz}$ and in the range $3.5-6 \mathrm{~Hz}$ associated with amplitude 2.5 and 3.5, respectively, are shown in Fig. 9a.

\subsubsection{Construction of the subsurface model using HVSR and MASW}

The geotechnical data, which could contribute to 
constructing the subsurface model in the Ein Boqeq north site, are shown in Table 2. They are collected from borehole EB-2 (Fig 5b), refraction survey and MASW measurement. Note that the shallow salt layer at a depth of $27 \mathrm{~m}$ is clearly detected by both refraction survey and MASW methods (Figs. 8a and 8b). Additionally, the MASW method provides us Vs of this salt layer and the underlying layers composed of gravel and lime carbonate. The optimal analytical function superimposed on the average spectral ratio is shown in Fig. 9b. The best fit of analytical (dashed line in Fig. 9b) and empirical (solid line) estimations is reached by assuming the thickness of the gravel-clay-limestone layer equal to $135 \mathrm{~m}$ and Vs of the deep reflector (the most likely another salt layer) is $1500 \mathrm{~m} / \mathrm{sec}$. We note that thickness and Vs of layers in the upper part of the subsurface model are kept as they are in the MASW section or with minor changes.

Thus, the deep reflector depth estimated using HVSR method combines with geophysical survey is $190 \mathrm{~m}$. The optimal subsurface model is given in Table 3.
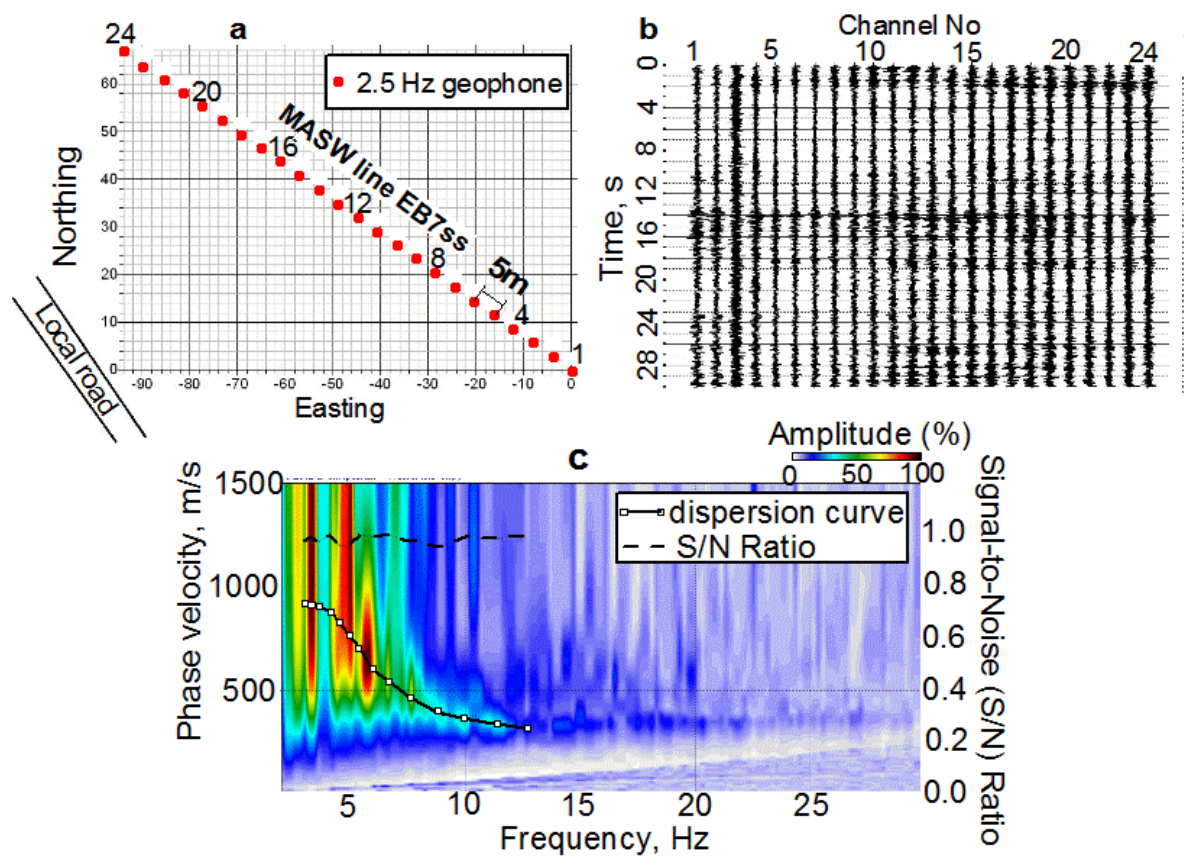

Fig. 6 Ein Boqeq site results. (a) Passive MASW roadside array, $5 \mathrm{~m}$ separation; (b) field records, 30s length, sample rate, $4 \mathrm{~ms}$; and (c) dispersion image with extracted dispersion curve (See Fig. 5c for location). Relative coordinates in meters; Intensity of traffic: 1 car and 1 bus during 1 minute

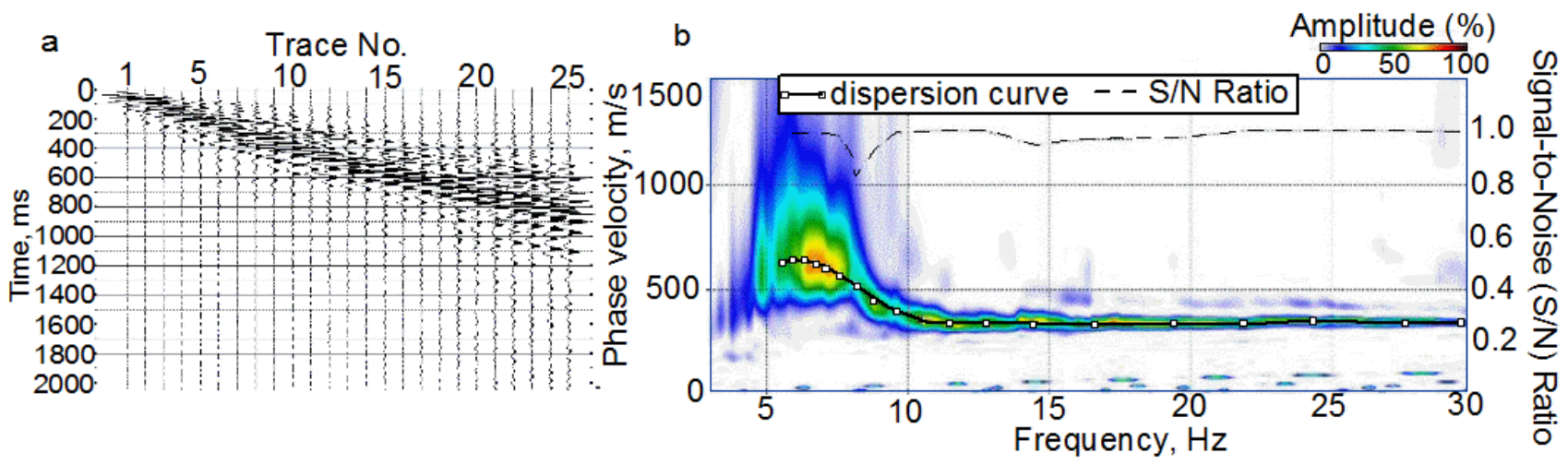

Fig. 7. Active MASW data along line EB7SS in the Ein Boqeq north site. (a) Field records acquired using active source; (b) Dispersion image (DT) generated from active record: squares are points of the extracted dispersion curve. The DT image comprises mainly fundamental mode and allows extracting the fundamental mode of dispersion curve 

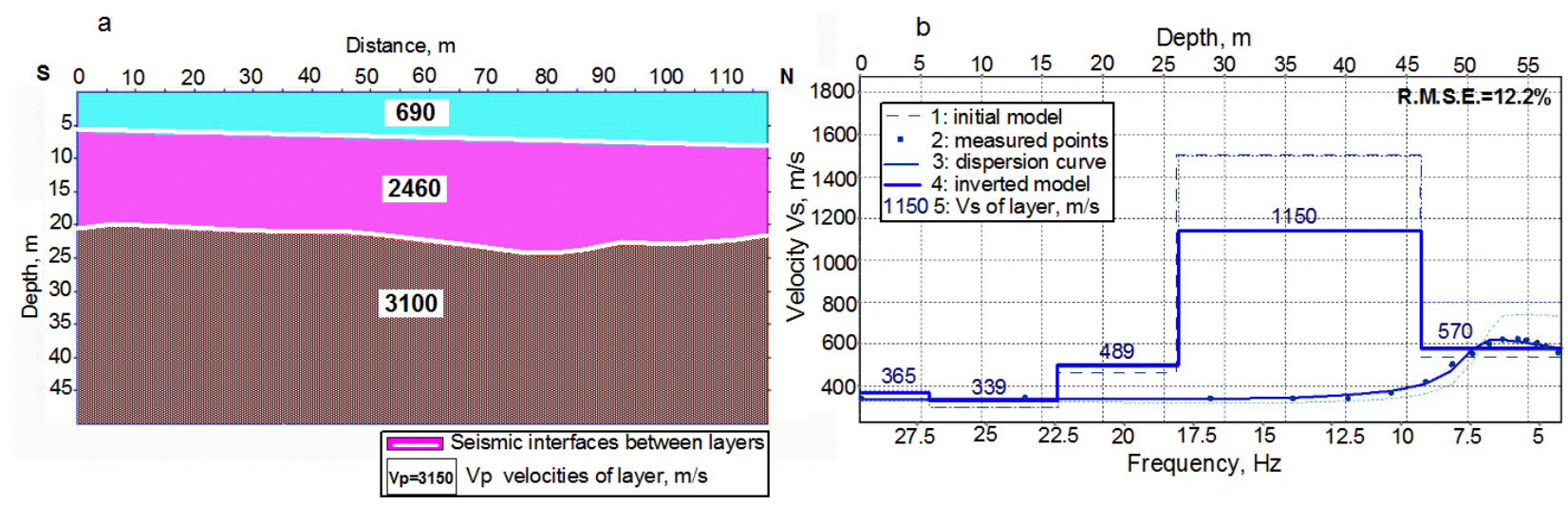

Fig. 8 Ein Boqeq north site. (a) Seismic refraction Vp depth velocity section along line 7ss; (b) Velocity versus depth function obtained by inversion of combined dispersion curve shown in Fig. 4a for 5 layered model. Denoted: Initial model (thin blue dotted line), corresponding initial dispersion curve (thin green dotted line), experimental points (blue rhombs) and fitted dispersion curve (blue solid line), inverse depth velocity model (blue layered graph). Lower horizontal axis is frequency $(\mathrm{Hz})$ and top axis is depth $(\mathrm{m})$

Table 1 Parameters of the inversion procedure for 6 layered model (Ein Boqeq North, Line EB7ss)

\begin{tabular}{|c|l|c|c|c|c|c|}
\hline $\begin{array}{c}\text { Layer } \\
\mathbf{N o}\end{array}$ & $\begin{array}{c}\text { Depth range } \\
\mathbf{m}\end{array}$ & $\begin{array}{c}\text { Initial model } \\
\mathbf{m} / \mathbf{s}\end{array}$ & $\begin{array}{c}\text { Inverted model } \\
\mathbf{m} / \mathbf{s}\end{array}$ & $\begin{array}{c}\text { R.M.S.E of Vs } \\
\mathbf{\%}\end{array}$ & $\begin{array}{c}\mathbf{V p} \\
\mathbf{m} / \mathbf{s}\end{array}$ & $\begin{array}{c}\text { Density } \\
\mathbf{k g} / \mathbf{m}^{3}\end{array}$ \\
\hline 1 & $0-6$ & 380 & 365 & 11.7 & 930 & 1550 \\
\hline 2 & $6.0-16.0$ & 300 & 330 & 6.02 & 706 & 1640 \\
\hline 3 & $16.0-26.0$ & 500 & 480 & 8.7 & 1224 & 1730 \\
\hline 4 & $26.0-46.0$ & 1500 & 1150 & 12.0 & 3500 & 2100 \\
\hline 5 & Under 46.0 & 800 & 570 & 10.00 & 1220 & 1910 \\
\hline
\end{tabular}
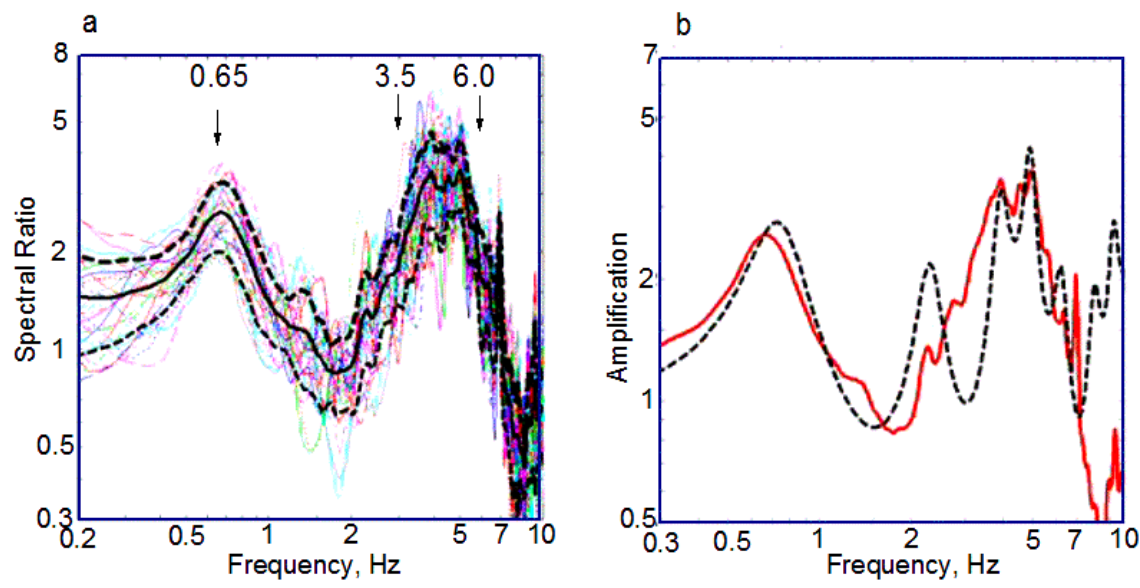

Fig. 9 (a) Individual and average $\mathrm{H} / \mathrm{V}$ spectral ratios \pm standard deviation obtained at point $\mathrm{EB}-2$ (digits show frequency of the ratio maximum); (b) Analytical transfer function (dashed line) in comparison with $\mathrm{H} / \mathrm{V}$ spectral ratio of ambient noise obtained at the Ein Boqeq north site (solid line)

\subsection{Ramat Hakovesh, (the Town of Tira, Central Israel)}

\subsubsection{Geological outline}

The investigated area is situated in the center of Israel (Fig. 10a) close to the town of Tira (Fig. 10b), a few kilometers west to the Shomron
Mountains slope represented by hard carbonates of the Judea Gr. (Turonian-Cenomanian age). The plain is filled by heterogeneous sediments of the Pleistocene age, mainly represented by clayey and sandy soils of 70-100 m thick as it is seen from section of the borehole 1A (Fig. 10c) located at the investigation site (Fig. 10d). 
Table 2 Geotechnical parameters used for analytical site response determination (Ein Boqeq north site)

\begin{tabular}{|c|c|c|c|c|c|}
\hline \multicolumn{2}{|c|}{ Borehole EB-2 } & \multicolumn{2}{|c|}{$\begin{array}{l}\text { P-wave Refraction Line EB- } \\
7 \mathrm{ss}\end{array}$} & \multicolumn{2}{|c|}{ MASW EB7SS array } \\
\hline Lithology & $\begin{array}{c}\text { Depth range } \\
\text { m }\end{array}$ & $\begin{array}{c}\text { Depth range } \\
\text { m }\end{array}$ & $\begin{array}{l}\mathrm{Vp} \\
\mathrm{m} / \mathrm{sec}\end{array}$ & $\begin{array}{c}\text { Depth range } \\
\mathbf{m}\end{array}$ & $\begin{array}{l}\text { Vs } \\
\mathrm{m} / \mathrm{sec}\end{array}$ \\
\hline Sand and gravel & $0-5$ & 0 to $5-8$ & 690 & $1-5$ & $\mathrm{LRZ}^{*}$ \\
\hline \multirow{2}{*}{ Gravel and sand } & \multirow{2}{*}{$5-27$} & \multirow{2}{*}{$5-8$ to $22-25$} & \multirow{2}{*}{2490} & $5-12$ & 300 \\
\hline & & & & $12-27$ & 410 \\
\hline $\begin{array}{l}\text { Salt with sand, clay } \\
\text { and gravel layers }\end{array}$ & $27-62$ & Below 22-25 & $2590-3930$ & $27-47$ & 1200 \\
\hline $\begin{array}{l}\text { Gravel, clay, and } \\
\text { limestone }\end{array}$ & Below 62 & -- & -- & Below 47 & 550 \\
\hline
\end{tabular}

*Low resolution zone

Table 3 Optimal 1-D subsurface model for determination of analytical site response function at the Ein Boqeq north site

\begin{tabular}{|c|c|c|c|c|c|}
\hline Layer & $\begin{array}{c}\text { Thickness } \\
\mathbf{m}\end{array}$ & $\begin{array}{c}\text { Depth to layer bottom } \\
\mathbf{m}\end{array}$ & $\begin{array}{c}\mathbf{V}_{\mathbf{S}} \\
\mathbf{m} / \mathbf{s e c}\end{array}$ & $\begin{array}{c}\text { Density } \\
\mathbf{k g} / \mathbf{m}^{\mathbf{3}}\end{array}$ & Damping \% \\
\hline 1 & 5 & 5 & 200 & 1600 & 5 \\
\hline 2 & 5 & 10 & 300 & 1600 & 5 \\
\hline 3 & 17 & 27 & 410 & 1800 & 4 \\
\hline 4 & 28 & 55 & 1200 & 2100 & 1 \\
\hline 5 & 135 & 190 & 600 & 1800 & 2 \\
\hline Half-space & $\infty$ & - & 1500 & 2000 & -- \\
\hline
\end{tabular}

\subsubsection{Schema of measurements}

The measurement schema is shown in Fig. 10d. Two seismic refraction lines (P-wave line of 320 $\mathrm{m}$ long and S-wave line of $250 \mathrm{~m}$ long) were shot in 2007. MASW lines SS-10, SS-5, and SS-2.5 of $250 \mathrm{~m}, 150 \mathrm{~m}$ and $72.5 \mathrm{~m}$ long, respectively, comprising of $2.5 \mathrm{~Hz}$ geophones (with separation of $10 \mathrm{~m}, 5 \mathrm{~m}$, and $2.5 \mathrm{~m}$, respectively) were shot in 2014. HVSR of ambient noise was obtained at point $11 \mathrm{w}$ situated close to borehole $1 \mathrm{~A}$.

\subsubsection{MASW results}

Dispersion images obtained for different data (different separation between geophones, active and passive sources, combined images) are presented in Fig. 11. Note that active dispersion curves for $10 \mathrm{~m}$ separation (Fig. 11a) are in the range of 4-12 Hz, similar images for $2.5 \mathrm{~m}$ separation wide, the frequency range to $3-23 \mathrm{~Hz}$
(Fig. 11b), and passive image extends the lowfrequency range to $2.5 \mathrm{~Hz}$, whereas highfrequency decreases to $9 \mathrm{~Hz}$ (Fig. 11c). Combining the different images allows getting a frequency range between $2.5 \mathrm{~Hz}$ and $23 \mathrm{~Hz}$ and a reach-resolution (penetration of waves) of 1 wavelength in the deep part and the resolution in shallow depth to $2.5 \mathrm{~m}$ from surface.

Inversion was carried out with the following constraints: top of reflector is located at a depth of $73.5 \mathrm{~m}, \mathrm{Vp}=3230 \mathrm{~m} / \mathrm{s}$ based on seismic refraction section (Fig. 12a)

Inversion was carried out with $\mathrm{Vp}$ fixed and Poisson's Ratio varying. 5-layered model with half space located at $73.5 \mathrm{~m}$ gives best result with R.M.S.E. $=9.9 \%$. Vs of half space is evaluated as $1480 \mathrm{~m} / \mathrm{s}$. Inversion results for 5-layered model are shown in Fig. 12b and in Table 4. 

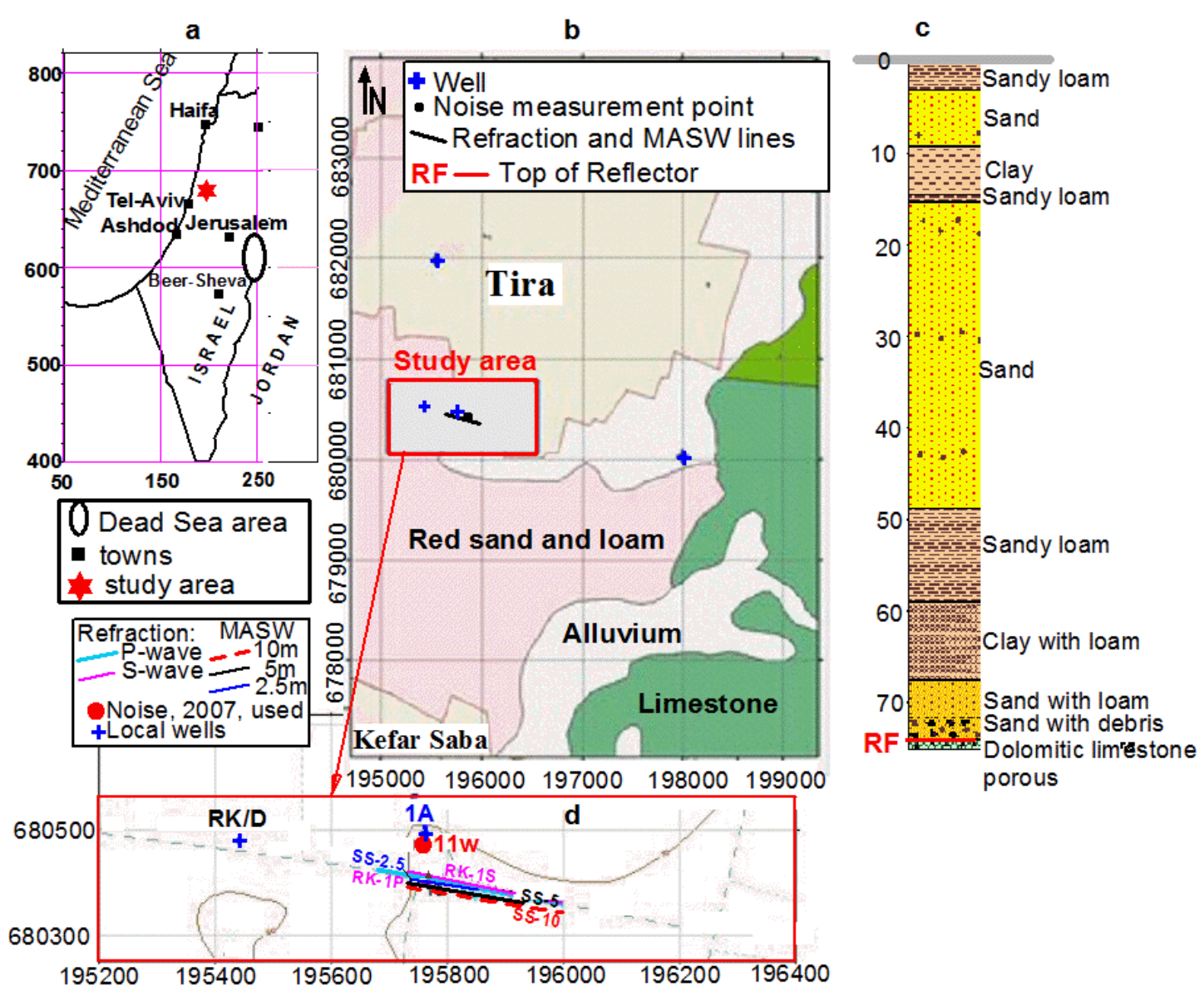

Fig. 10 General map of Ramat Hakovesh site location. (a) Israel map and test site location; (b) Geological map showing the study area relative to the Tira town; (c) General lithological section of the Ramat Hakovesh based on 1A test borehole (see Fig.10d for location); (d) measurement layouts. RF (top of dolomite) is located at a depth of $73.5 \mathrm{~m}$ in borehole $1 \mathrm{~A}$ (test well)

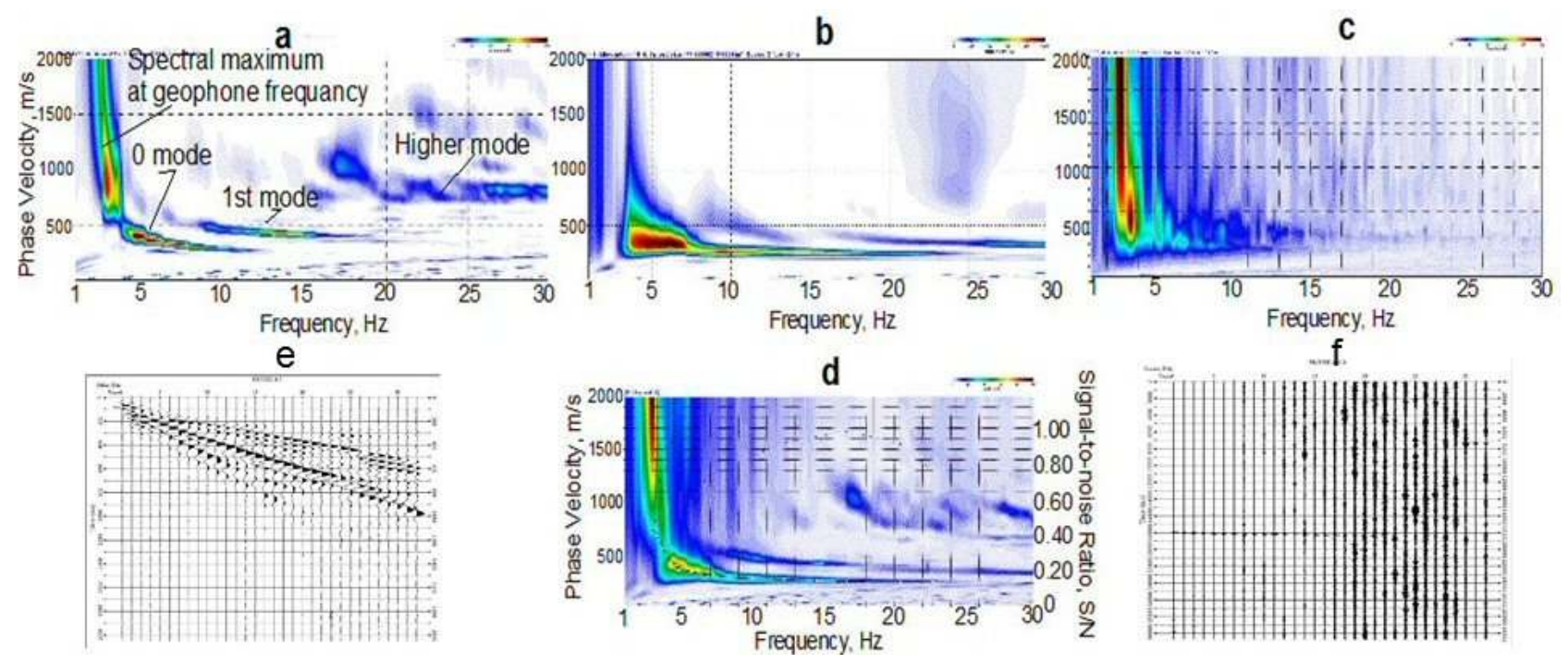

Fig. 11 Four dispersion curves extracted from surface wave records from different MASW measurements: (a) active source along a 26-channel line with a geophone separation of $10 \mathrm{~m}$ (250 m length); (b) active source along 31 channel line with separation $2.5 \mathrm{~m}$ between geophones (77.5 m length); (c) ambient noise (passive source) along 26 channel line $10 \mathrm{~m}$ separation; (d) combined dispersion curve combined from (a) - (c) images; (e) and (f) are field records of active and passive sources, respectively 

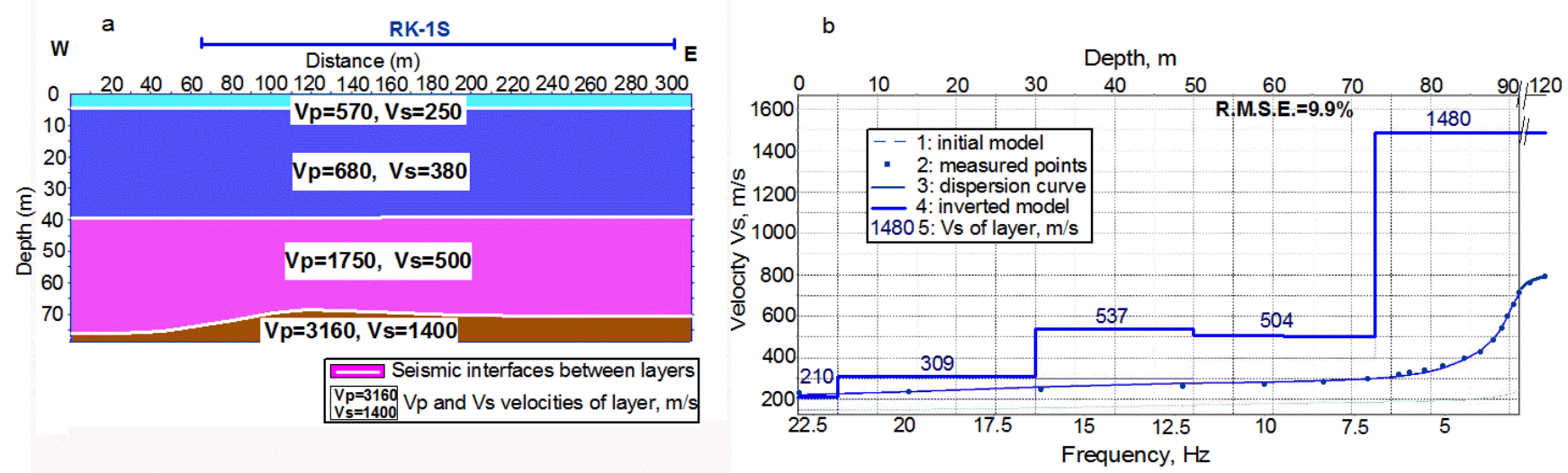

Fig. 12 Ramat Hakovesh site. Velocity versus depth function obtained by inversion of combined dispersion curve shown in Fig. 5b for 5 layered model with half space as foundation. Denoted: as Fig. 8b. Vertical axis is Vs, upper horizontal axis is depth, and lower one is the frequency

Table 4 Depth Vs profile derived from MASW and optimal 1-D subsurface model for determination of analytical site response function at the Ramat Hakovesh site

\begin{tabular}{|l|c|c|c|c|}
\hline \multirow{2}{*}{ Lithology } & \multicolumn{2}{|c|}{ MASW } & \multicolumn{2}{c|}{ MASW+HVSR optimal model } \\
\cline { 2 - 5 } & $\begin{array}{c}\text { Depth } \\
\mathbf{m}\end{array}$ & $\begin{array}{c}\text { Vs } \\
\mathbf{m} / \mathbf{s e c}\end{array}$ & $\begin{array}{c}\text { Depth } \\
\mathbf{m}\end{array}$ & $\begin{array}{c}\text { Vs } \\
\mathbf{m} / \mathbf{s e c}\end{array}$ \\
\hline Alluvium & $0-5$ & 205 & $0-5$ & 170 \\
\hline \multirow{3}{*}{$\begin{array}{l}\text { Sand, loam, clay, calcareous } \\
\text { sandstone }\end{array}$} & $5-30$ & 300 & $5-30$ & 235 \\
\cline { 2 - 5 } & $30-50$ & 500 & $30-55$ & 450 \\
\cline { 2 - 5 } & $50-73$ & 490 & $55-70$ & 520 \\
\hline Broken dolomite, limestone & $73-240$ & 1480 & $70-260$ & 1430 \\
\hline Dolomite & below 240m & -- & -- & 2400 \\
\hline
\end{tabular}

\subsubsection{HVSR results}

Measurements of ambient vibrations were carried out close to the experimental borehole $1 \mathrm{~A}$ where detailed information on the subsurface down to a depth of $75 \mathrm{~m}$ is available. The prominent feature of the individual and average spectral ratios shown in Fig. 13a is two inseparable peaks at frequencies of 1.4 and $1.9 \mathrm{~Hz}$. Such distribution of peaks could be construed as follows: while the first resonance peak is related to the hard rock at depth, the second peak is caused by intermediate hard layer directly overlying the deep reflector.

\subsubsection{Combination of HVSR and MASW methods}

In the velocity-depth section obtained from MASW measurements (Fig. 12b), four layers could be identified. As seen in the lithological section of the borehole 1A (Fig. 10c) layered Vs may be correlated with sandy loam (Vs $=205$ $\mathrm{m} / \mathrm{sec})$; sand $(\mathrm{Vs}=300 \mathrm{~m} / \mathrm{sec})$; clay and sandy loam $(\mathrm{Vs}=500 \mathrm{~m} / \mathrm{sec})$ that overlies the broken dolomitic limestone $\left(\mathrm{V}_{\mathrm{S}}=1440 \mathrm{~m} / \mathrm{sec}\right)$. These data are presented in Table 4 . Slightly different section was extracted from refraction survey along P-S lines, shown in Fig. 12a. The response function calculated using solely geophysical data and the broken dolomitic limestone at a depth of $73 \mathrm{~m}$ as a fundamental reflector is shown in Fig. $13 \mathrm{~b}$ (blue solid line). It is clearly seen that there is no satisfactory consent between the calculated function and HVSR neither in amplitude nor in shape. In particular, the calculated function exhibits a single resonance peak with amplitude of 3.5 at resonance frequency $1.6 \mathrm{~Hz}$, while $\mathrm{HV}$ spectral ratio yields two resonance peaks at 1.4 
and $1.9 \mathrm{~Hz}$ with associated amplitudes of 7 and 5.5 respectively. Therefore, in the second step, we supposed the subsurface model, in which the broken dolomite-limestone is an intermediate hard layer and overlays the fundamental reflector (dolomite) at a depth which should be estimated. The result of the optimization procedure is shown in Fig.13b. The optimal model providing the best fit between HVSR and calculated response function is given in Table 4 as well.
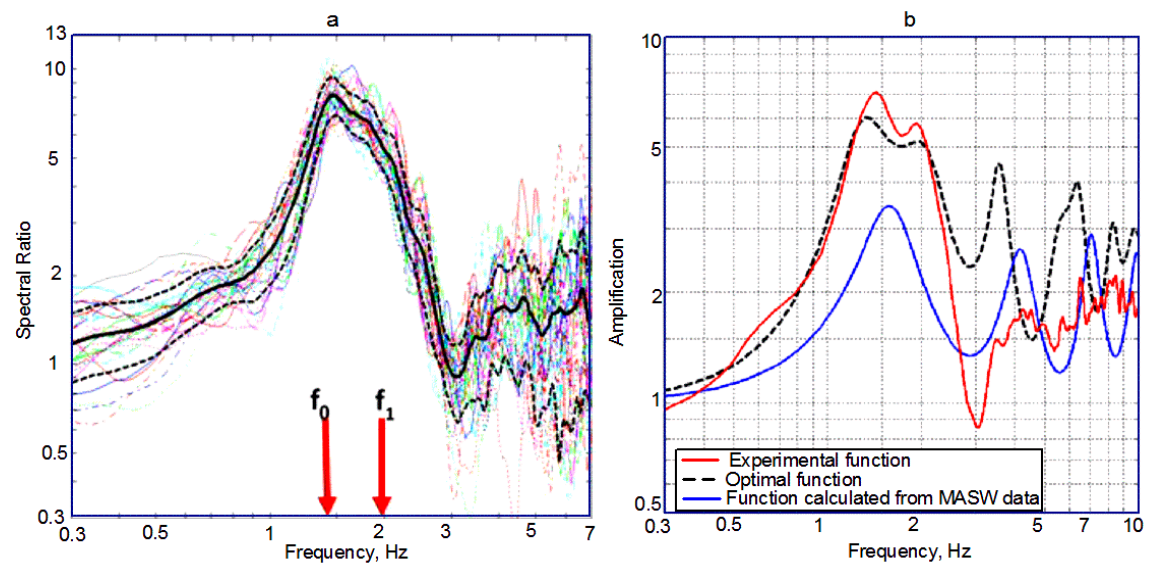

Fig. 13 (a) horizontal-to-vertical spectral ratios (individual, average and standard deviation) obtained in Ramat Hakovesh site. Arrows show the fundamental $f_{0}$ and second resonance $f_{1}$ frequencies; (b) HVSR curve (red solid line) superimposed on analytical function calculated using MASW results only (blue line) and obtained by combination of HVSR and MASW methods (dashed line)

\section{Discussion and conclusions}

Any analytical procedure (making use of a computer code) needs a model of the site's subsurface to facilitate the computations. Based on numerous investigations it can be concluded that there is no one single technique that will provide a model good enough for site response evaluations. The spectral ratio method reveals key information about the dynamic characteristics of the subsurface and should be used to help construct the subsurface model. In most of recent researches carried out in Israel, the reliable subsurface models could be reached by integrating information from empirical HVSR, and available geological, borehole, and geophysical data (Zaslavsky et al 2009). While combination of seismic methods provides the Vs model for the uppermost tens of meters, HVSR method adds information and constraints for the development of a subsurface model at significantly greater depths (hundreds of meters).

In this study, we explored the potential of the Multichannel Analysis of the Surface Wave (MASW) method to provide shallow Vs models for two sites where seismic refraction or downhole methods were applied in the earlier investigations. Noting the high quality of the Swave refraction method in constructing subsurface models (Palmer 1986) we have to resume very shallow, as a rule, Vs sections derived from this survey (Fig 2). Deeper penetration of surface waves enables constructing deeper Vs sections and facilitates their optimization in combination with the HVSR method. Moreover, the system of shooting used in the MASW method enables us also simultaneously to carry out a seismic refraction line at the same disposition, geophones and stroke to get the Vp section used as a constraint.

MASW is usually performed in 3 modifications: (1) passive, (2) active, and (3) combined (passive + active). Our experience testifies that generally, all three MASW modifications would give similar Vs sections when the signal is strong enough (Signal-to-Noise Ratio $=0.8-1.0)$ and the same initial layered model is used for inversion procedure. In this case, frequency range can be very similar. Such a case is the Dam 5 study in the south of the Dead Sea (Ezersky et al 2013b). However, in most 
cases, passive and active MASW modes differ in the frequency range. Passive MASW is shifted to the low-frequency range, while active MASW to the relatively high-frequency range.

In the Ein Boqeq site passive MASW signal was measured in the range of $2.5-12.0 \mathrm{~Hz}$ (Fig. $6 \mathrm{c})$, whereas active signal was measured in the range of $5.9-30 \mathrm{~Hz}$ (Fig. 6b). Such a difference in the frequency range results in the different wavelength and, respectively, in the resolution of inversion results at the maximum depth and minimum (shallow) depth. In the latter example, passive MASW shows higher wavelength at lowfrequency $\lambda_{\text {max }}=174 \mathrm{~m}$ than the active one $\left(\lambda_{\max }=117 \mathrm{~m}\right)$. At the same time, the active MASW shows lower wavelength at higher frequencies $\left(\lambda_{\min }=11.6 \mathrm{~m}\right)$ as against $\lambda_{\min }=27.3 \mathrm{~m}$ measured with the passive method. Combining the two methods enables widening the frequency range to $2.5-30 \mathrm{~Hz}$ and estimating the maximum penetration depth $Z_{\text {max }}$ in the range of 87-174 m (e.g. $90 \mathrm{~m}$, at least) and the minimum penetration depth $H_{1}\left(=\lambda_{\text {min }} / 2\right)$ as 5.8 $\mathrm{m}$ with determined resolution in the upper part of the section in active MASW.

Table 2 shows that seismic refraction method allows constructing the Vs section down to $25 \mathrm{~m}$ deep, whereas MASW enables constructing Vs section below $47 \mathrm{~m}$ deep (including salt layer and underlain sediments) that considerably facilitate construction of optimal model.

A common feature of $\mathrm{H} / \mathrm{V}$ spectral ratios obtained at Ein Boqeq north site is two resonance peaks at $0.65 \mathrm{~Hz}$ and in the range of 3.5-6 Hz. (Fig. 8a). While the fundamental frequency is related to the hard rock in depth, the position of the second resonance peak is determined by an intermediate hard layer in the subsurface. The shallow salt layer connected with the second resonance frequency is identified by the number of boreholes (Fig. 4b, for instance) as a salt layer found at a depth of 20-30 m and it is confidently detected by both refraction and MASW methods (Fig. 7a and 7b). We suggest that the deep reflector is most likely also salt. Such assumption is supported by data from deep boreholes (Gardosh et al 1997). The depth and Vs of the deep reflector are adjusted.

This case is an example of successful use of the combined MASW and HVSR methods for estimating subsurface model down to the depth of about $200 \mathrm{~m}$ when the geological model comprises two hard layers within the soft sediments.

In the Ramat Hakovesh site the following geophysical measurements were carried out close to $1 \mathrm{~A}$ borehole at different times: $\mathrm{P}$ and S-wave refraction survey, downhole and MASW measurements (Fig. 10d). The MASW survey was performed in passive, active, and combined modifications. All the Vs versus depth graphs, namely S-wave refraction section (thin solid line), downhole (thick dashed line) and MASW based ones (thick dashed line) derived from the combined dispersion curve (Fig. $4 \mathrm{~b}$ ) are shown in Fig. 14. The optimal model calculated from a combination of MASW and HVSR methods is also shown by a thick solid line. General Vs depth trend is presented by a dashed line marked by circles.

From the comparative graph presented, it is clearly seen that the depth of Vs sections obtained from different methods vary significantly. The

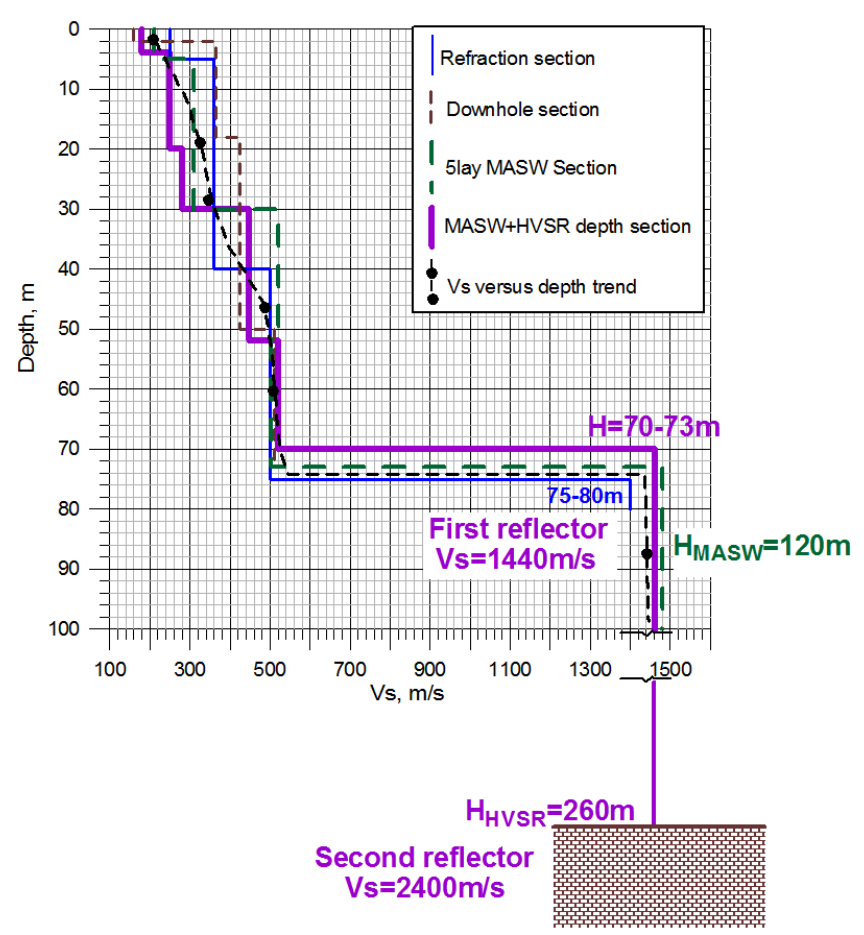

Fig. 14 Comparison between different Vs versus depth models derived by different methods 
refraction Vs model based on $250 \mathrm{~m}$ line with separation of $10 \mathrm{~m}$ between geophones has penetration depth of maximum $75 \mathrm{~m}$ approximately. The downhole characterizes Vs structure down to a depth of $68-70 \mathrm{~m}$, which is the depth where drilling met a karstified carbonate and was stopped. The extraction of the drilling instrument from the borehole caused a collapse and the lowermost part of borehole was filled with sediment. MASW penetration depth is evaluated from wavelength; that is $\lambda_{\text {max }}=V_{p h_{\text {max }}} / f_{\text {min }}=239 \mathrm{~m}$ and penetration depth is evaluated as between $120 \mathrm{~m}$ and $240 \mathrm{~m}$ (accepting $\left.Z_{\text {max }}=(0.5-1.0) \cdot \lambda_{\text {max }}\right)$, e.g. $120 \mathrm{~m}$ at least.

Comparing the velocity structure of different graphs with the optimal one derived from combined MASW and HVSR methods one can see that the Vs versus depth trend shows the gradual increase of Vs with the depth from $200 \mathrm{~m} / \mathrm{s}$ near surface to $550 \mathrm{~m} / \mathrm{s}$ at a depth of refractor $(70-73 \mathrm{~m})$. With the general similarity, graphs slightly differ from the optimal graph (by $50-100 \mathrm{~m} / \mathrm{s}$ ) at small (up to $40 \mathrm{~m}$ ) depths. The largest deviation is observed between refraction and downhole graphs. At depths greater than 40 $\mathrm{m}$, all graphs are converged. Finally, shear-wave velocity of half space measured by S-wave refraction method as $1400 \mathrm{~m} / \mathrm{s}$ has been evaluated by MASW method as $1480 \mathrm{~m} / \mathrm{s}$. After optimization of the Vs-depth graph we obtain $\mathrm{Vs}=1440 \mathrm{~m} / \mathrm{s}$ and overlain soil velocities as shown in Fig. 14 (thick solid graph).

The discrepancy between the Vs for shallow subsurface sediments can be caused by several reasons. The downhole located at approximately $70 \mathrm{~m}$ north of Refraction and MASW lines is affected, evidently, by features of shallow subsurface properties. In addition, the downhole is also affected by the construction of the borehole walls, quality of drilling, cementation and properties of the cement, required by the ASTM D4428/D4428M, (1991(1995)). It requires an experienced drilling crew. Deviation of refraction Vs section can be caused by a large separation $(10 \mathrm{~m})$ between geophones that provides with low depth resolution at shallow depths and more than that at greater depths.
As is seen from a comparison of penetration depths, S-wave refraction graph characterizes only uppermost part of rock foundation ( 73-80 $\mathrm{m})$, whereas the MASW method characterizes depths down to $120 \mathrm{~m}$, at least. No variations of $\mathrm{Vs}$ were revealed in this depth range. We also note that quality of the MASW signal is significantly higher than the refraction one (Figs. $2 \mathrm{~d}$ and $2 \mathrm{c}$, respectively). This provides a more reliable velocity-depth section obtained from the MASW method. A good match between the analytical function and experimental spectral ratio was reached when we extended the intermediate hard layer down to a depth of $250 \mathrm{~m}$ while retaining Vs profile obtained from MASW (Fig. $13 \mathrm{~b}$ ) and added fundamental reflector composed of dense dolomite with $\mathrm{Vs}=2400 \mathrm{~m} / \mathrm{s}$. This velocity value agrees well with Vs measured in samples in the Technion laboratory (Frydman 2007).

Conclusions. In this study, we replaced Swave seismic refraction survey by MASW method in its active and passive modifications using $2.5 \mathrm{~Hz}$ geophones, and optimized data acquisition and processing that improved resolution of Vs section down to the bedrock located at $100 \mathrm{~m}$ depth and more.

The MASW method has the following main advantages: (1) It is not limited by reverse velocity structure; (2) It is based on highly energetic surface waves that provides good quality records; and (3) It is a low-cost, efficient, and relatively fast method. At the same time, constructing an initial Vs model and applying constraints on the results of inversion are necessary.

The methodology of joint use of HVSR (based on ambient noise) and Multichannel Analysis of Surface Waves (MASW) based on surface wave records excited by seismic source (active MASW) or ambient noise (passive one) has been improved and tested in Israel, where the salt layers on the Dead Sea coast and hard carbonates in the plain areas of Israel serve strong seismic wave reflectors. The main issue discussed is: whether resolution of the MASW method is enough to adequately replace and improve the refraction techniques.

At the two characteristic test sites, a 
combination of MASW and HVSR methods made it possible:

1. on the Ein Boqeq site (south of the Dead Sea), to construct the subsurface structure down to a depth of about $200 \mathrm{~m}$ and to detect two firm reflectors composed of salt rock separated by soft sediments;

2. on the Ramat Hakovesh site (plain area in the Centre of Israel), to reveal that unlike borehole and refraction survey data, the fundamental reflector is the compact high velocity dolomite located at a depth of $260 \mathrm{~m}$, while the fractured limestone located at a depth of $73 \mathrm{~m}$ overlying the dolomite is an intermediate layer.

\section{Acknowledgement}

This publication was made possible through support provided by the Ministry of Energy and Water Resources of Israel (Contracts No. 211-17007 and 213-17-004). We thank the M. Kalmanovich for providing geological materials. We are grateful also to V. Giller and P. Portnov who acquire the data in complicated climate conditions. We thank G. Rix for cooperation. We are very grateful to anonymous reviewers whose great efforts allowed improvement of the manuscript.

\section{References}

ASTM, 1991(1995). Standard D4428/D4428M. Standard Test Methods for Crosshole Seismic Testing.

ASTM, 2007. Standard D7400. Standard Test Methods for Downhole Seismic Testing. ASTM International, USA.

Bodet, L., K. Van Wijk, A. Bitri, O. Abraham, P. Côte, G. Grandjean and D. Leparoux, 2005. Surface-wave inversion limitations from laser-Doppler physical modeling. Journal of Environmental and Engineering Geophysics, 10: 151 - 162 .

Bonnefoy-Claudet, S., F. Cotton and P.Y. Bard, 2006. The nature of the seismic noise wave field and its implication for site effects studies: a literature review. Earth Sci. Rev. 79(3-4): $205-227$.

Boor, D.M., B.V. Joyner and T.E. Fumal, 1997.
Equations for estimating horizontal response spectra and peak accelerations from western North American earthquakes: a summary of recent work. Seismological Research Letters, 68(1): 128 - 153.

BSSC, 1994. NEHRP recommended provisions for seismic regulations for new buildings, Part 1- Provisions, FEMA 222A. Federal Emergency Management Agency, 290p.

Ezersky, M., L. Bodet, E. Akkawi, A. Al-Zoubi, C. Camerlynck, A. Dhemaied and P.Y. Galibert, 2013a. Seismic Surface-wave prospecting methods for sinkhole hazard assessment along the Dead Sea shoreline. Journal of Environmental and Engineering Geophysics, 18(4): 233 - 253. DOI: 10.2113/JEEG18.4.233.

Ezersky, M., M. Gorstein, M. Kalmanovich and N. Perelman, 2013b. Combining H/V spectral ratio (HVSR) technique with method using surface waves (MASW) to map the subsurface: implementation in the Dead Sea area. Unpublished GII Report 025/759/13.

Fäh, D., F. Kind and D. Giardini, 2001. A theoretical investigation of average $\mathrm{H} / \mathrm{V}$ ratios. Geophys. J. Int., 145(2): 535 - 549. DOI: 10.1046/j.0956-540x.2001.01406.x.

Frydman, S., 2007. Geotechnical study of site response Ramat Hakovesh. National Building research Institute. Unpublished Report No. 2006686, 166p.

Gardosh, M., E. Kashai, S. Salhov, H. Shulman and E. Tannenbaum, 1997. Hydrocarbon exploration in the southern Dead Sea area. The Dead Sea: the lake and its setting. Oxford University Press, Oxford, pp: 57 - 71.

Jakosky, J., 1957. Exploration geophysics: Trija Publishing Company, Los Angeles, 1195p.

Jarpe, S. P., C. H. Cramer, B.E. Tucker and A.F. Shakal, 1988. A comparison of observations of ground response to weak and strong motion at Coalinga, California. Bull. Seism. Soc. Am., 78: 421 - 435.

Kagami, H., C.M. Duke, G.C. Liang and Y. Ohta, 1982. Observation of $1-$ to 5-second microtremors and their application to earthquake engineering. Part II. Evaluation of site effect upon seismic wave amplification deep soil deposits. Bull. Seism. Soc. Am., 72: 
$987-998$.

Lachet, C. and P.Y. Bard, 1994. Numerical and theoretical investigations on the possibilities and limitations of the Nakamura's technique. J. Phys. Earth, 42: 377 - 397.

Lermo, J. and F. J. Chávez-García, 1994. Are microtremors useful in site response evaluation? Bull. Seism. Soc. Am., 84: 1350 1364.

Louie, J.N., 2001. Faster, better: shear-wave velocity to 100 meters depth from refraction microtremor arrays. Bull. Seism. Soc. Am., 91(2): 347 - 364.

Malischewsky, P. G. and P. Scherbaum, 2004. Love's formula and H/V-ratio ellipticity of Rayleigh waves. Wave Motion 40: 57-67.

Malischewsky, P.G., Y. Zaslavsky, M. Gorstein, V. Pinsky, T.T. Tran, F. Scherbaum and F. Estrela., 2010. Some new theoretical considerations about the ellipticity of Rayleygh waves in the light of site-effect studies in Israel and Mexico. Geofisica Internacional, 49(3): 141 - 152.

Mucciarelli, M. and M.R. Gallipoli, 2004. The HVSR Technique from Microtremor to Strong Motion: Empirical and Statistical Considerations. 13th World Conference of Earthquake Engineering, Vancouver, B.C., Canada, Paper 45.

Nakamura, Y., 1989. A method for dynamic characteristics estimation of subsurface using microtremor on the ground surface. Quarterly Report of RTRI, 30: 25 - 33.

Okada, H., 2003, The microtremor survey method. Geophysical Monograph Series, no. 12. published by Society of Exploration Geophysicists (SEG), Tulsa, OK.

O'Neill, A., 2003. Full-waveform Reflectivity for Modelling, Inversion and Appraisal of Seismic Surface Wave Dispersion in Shallow Site Investigations. Ph.D. thesis, The University of Western Australia, School of Earth and Geographical Sciences.

Palmer, D., 1986. Refraction Seismics. The Lateral Resolution of Structure and Seismic Velocity. Geophysical Press, LondonAmsterdam.

Park, C.B., 2006. SurfSeis. Active and passive MASW. User's Manual. V.2.0. M. Adkins-
Heljeson (ed), Kansas Geological Survey.

Kansas, USA, 40p.

www.kgs.ku.edu/software/surfseis/index.htm 1

Park, C.B., R.D. Miller and J. Xia, 1999. Multichannel analysis of surface waves. Geophysics, 64(3): 800 - 808.

Park, C.B., R.D. Miller, N. Ryden, J. Xia and J. Ivanov, 2005. Combined use of active and passive surface waves. JEEG, 10(3): 323 334.

Park, C.B. and R.D. Miller, 2006. Roadside Passive MASW. SAGEEP 2006, 12p.

Park, C.B., R.D. Miller, J. Xia and J. Ivanov, 2007. Multichannel analysis of surface waves (MASW) - active and passive methods. The Leading Edge, 26(1): 60 - 64.

Perelman, N. and Y. Zaslavsky, 2001. Analysis of Seismic Signals in Frequency Domain, (SEISPECT). Unpublished GII Report 569/345/01.

Richart, F. E., J. R. Hall and R. D. Woods, 1970. Vibrations of Soils and Foundations. Prentice Hall, Englewood Cliffs, 414p.

Rix, G.J. and A.E. Leipski, 1991. Accuracy and resolution of surface wave inversion. In: Bhatia S.K. and Blaney G.W. (eds.), Recent Advances in Instrumentation, Data Acquisition and Testing in Soil Dynamics: Am. Soc. Civil Eng. Geotechnical Special Publication No. 28, pp: 17 - 23.

Satoh, T., T. Sato and H. Kawase, 1995. Nonlinear behavior of soil sediments identified by using borehole records observed at the Ashigara valley, Japan. Bull. Seism. Soc. Am., 85: 1821 - 1834.

Scherbaum, F., K.G. Hinzen, M., Ohrnberger, 2003. Determination of shallow shear wave velocity profiles in the Cologne, Germany area using ambient vibrations, Geophys. J. Int. 152: 597 - 612.

Schnabel P.B., J. Lysmer and H. B. Seed, 1972. SHAKE: a Computer Program for Earthquake Response Analysis of Horizontally Layered Sites. Report No. EERC72-12, University of California, Berkeley.

Seekins, L.C., L. Wennerberg, L. Margheriti and H.P. Liu, 1996. Site amplification at fife locations in San Francisco, California: a 
comparison of $\mathrm{S}$ waves, codas and microtremors, Bull. Seism. Soc. Am., 86: 627 $-635$.

Shapira, A. and V. Avirav, 1995. PS-SDA Operation Manual. Unpublished IPRG Report No. Z1/567/79.

Shtivelman, V., 1999. Using surface waves for estimating the shear-wave velocities in the shallow subsurface onshore and offshore Israel. Europ. Journ. Env. Eng. Geoph., 4: 17 $-36$.

Socco, L.V. and C. Strobia, 2004. Surface-wave method for near-surface characterization: a tutorial. Near Surface Geophysics, 2: 165 185.

Socco, L.V., D. Boiero, S. Foti and R. Wisén, 2009. Laterally constrained inversion of ground roll from seismic reflection records. Geophysics, 74(6): G35 - G45.

Stokoe II, K.H., A. Kurtulus and K. Park, 2006. Development of field methods to evaluate the nonlinear shear and compression moduli of soil. Earthquake Geotechnical Engineering Workshop, Canterbury 2006 (EGE 2006), Christchurch, New Zealand, November 21 24, 2006.

Stokoe, K.H., S.G. Wright, J. Bay and J.M.

Roesset, 1994. Characterization of geotechnical sites by SASW method. In : Woods, R.D. (ed.), Geophysical Characterization of Sites (ISSMFE TC\#10), 15 - 25. Oxford and IBH Publishers.

Storn, R. and K., Price, 1995. Differential Evolution: A Simple And Efficient Adaptive Scheme For Global Optimization Over Continuous Spaces. Technical Report TR-95012, International Computer Science Institute, Berkeley.

Xia, J, R.D. Miller and C.B. Park, 1999. Estimation of near-surface shear-wave velocity by inversion of Rayleigh waves. Geophysics, 64(3): 691 - 700.

Xia, J., R.D. Miller, C.B. Park and G. Tian, 2003. Inversion of high frequency surface waves with fundamental and higher modes. Journal of Applied Geophysics, 52: 45 - 57.

Yamanaka, H., M. Takemura, H. Ishida and M. Niva, 1994. Characteristics of long-period microtremors and their applicability in exploration of deep sedimentary layers. Bull. Seism. Soc. Am., 84: 1831 - 1841.

Yechieli, Y., M. Abelson, A. Bain, V. Shtivelman, C. Onn, D. Wacks, G. Bar, R. Kalbo and V. Lyachovski, 2004. Sinkhole phenomena along the Dead Sea shore line. Unpublished GSI Report No. GSI/21/04 (in Hebrew).

Zaslavsky, Y., A. Shapira, M. Gorstein, M. Kalmanovich, V. Giller, N. Perelman, I. Livshits, D. Giller and I. Dan, 2005. Site response from ambient vibrations in the towns Lod and Ramle (Israel) and earthquake hazard assessment, Bulletin of Earthquake Engineering, 3(3): 355-381. DOI: 10.1007/s10518-005-1243-1.

Zaslavsky, Y., G. Ataev, M. Gorstein, M. Kalmanovich, A. Hofstetter, N. Perelman, T. Aksinenko, Giller, V., H. Dan, D. Giller, I. Livshits, A. Shvartsburg, and A. Shapira, 2008. Microzoning of site response parameters in the towns of Dimona and Bet Shean (Israel), Bollettino di Geofisica, teorica and applicate, 49(1): 109 - 130.

Zaslavsky Y., A. Shapira, G. Ataev, M. Gorstein, T. Aksinenko, M. Kalmanovich, N. Perelman and R. Hofstetter, 2009. Using Ambient Noise Measurements in the Process of Assessing Earthquake Hazards in Urban Areas: Examples from Israel. In: T. Miura and Y. Ikeda (eds), Earthquake Engineering: New research. Nova Publisher, 155 - 218.

Zaslavsky, Y., A. Shapira, M. Gorstein, N. Perelman, G. Ataev, T. Aksinenko, 2012. Questioning the applicability of soil amplification factors as defined by NEHRP (USA) in the Israel building standards. Natural Science, 4: 631 - 639. DOI: 10.4236/ns.2012.428083. 